\title{
Case Study: Ebus Hybrid Electric Buses and Trolleys
}

\section{Technical Report} NREL/TP-540-38749 July 2006

R. Barnitt

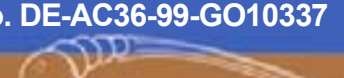




\section{Case Study: Ebus Hybrid Electric Buses and Trolleys}

\section{R. Barnitt}

Prepared under Task No. FC06.3000

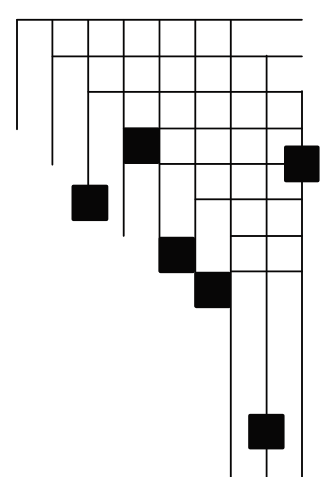




\section{NOTICE}

This report was prepared as an account of work sponsored by an agency of the United States government. Neither the United States government nor any agency thereof, nor any of their employees, makes any warranty, express or implied, or assumes any legal liability or responsibility for the accuracy, completeness, or usefulness of any information, apparatus, product, or process disclosed, or represents that its use would not infringe privately owned rights. Reference herein to any specific commercial product, process, or service by trade name, trademark, manufacturer, or otherwise does not necessarily constitute or imply its endorsement, recommendation, or favoring by the United States government or any agency thereof. The views and opinions of authors expressed herein do not necessarily state or reflect those of the United States government or any agency thereof.

Available electronically at http://www.osti.gov/bridge

Available for a processing fee to U.S. Department of Energy and its contractors, in paper, from:

U.S. Department of Energy

Office of Scientific and Technical Information

P.O. Box 62

Oak Ridge, TN 37831-0062

phone: 865.576.8401

fax: 865.576 .5728

email: mailto:reports@adonis.osti.gov

Available for sale to the public, in paper, from:

U.S. Department of Commerce

National Technical Information Service

5285 Port Royal Road

Springfield, VA 22161

phone: 800.553 .6847

fax: 703.605.6900

email: orders@ntis.fedworld.gov

online ordering: http://www.ntis.gov/ordering.htm 


\section{Table of Contents}

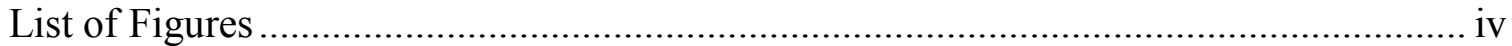

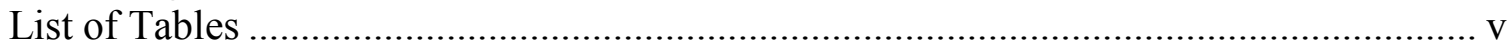

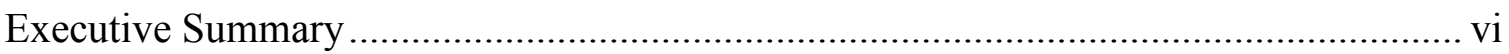

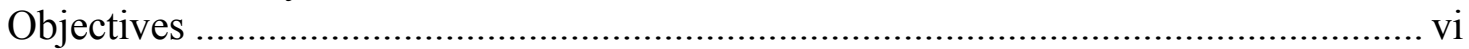

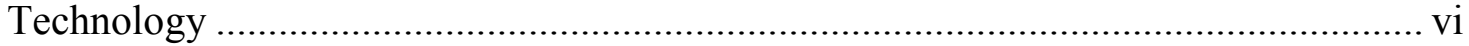

Evaluation Methods ................................................................................................ vii

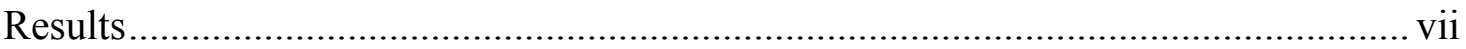

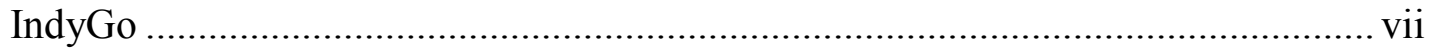

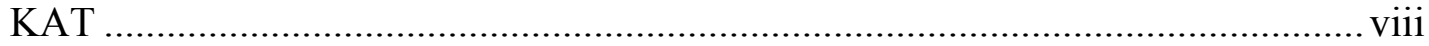

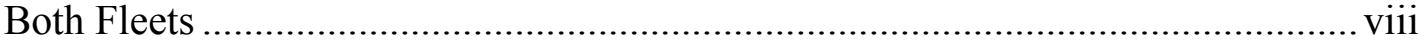

Overview: Ebus Hybrid Buses and Trolleys............................................................... 1

Capstone MicroTurbine APU .................................................................................. 2

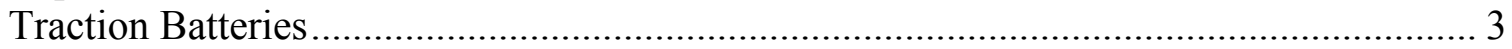

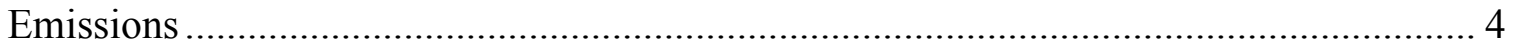

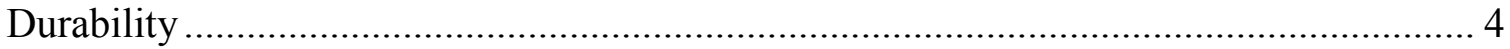

Project Design and Data Collection ............................................................................. 4

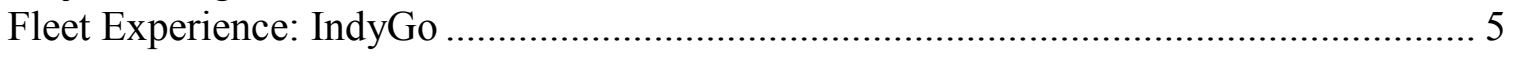

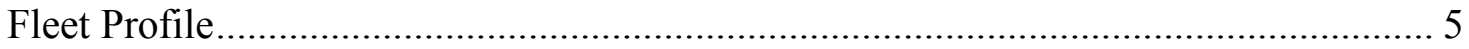

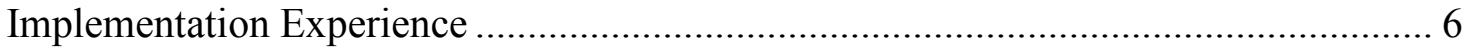

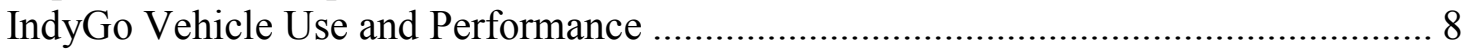

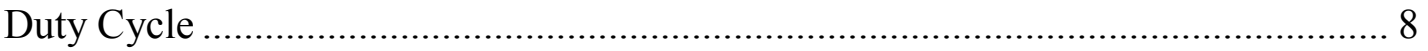

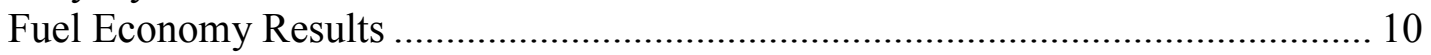

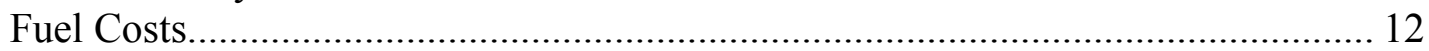

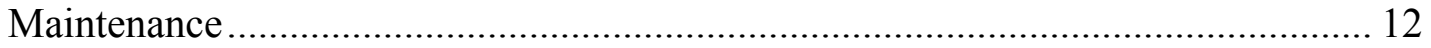

Specific Component Issues and Resolutions ........................................................ 14

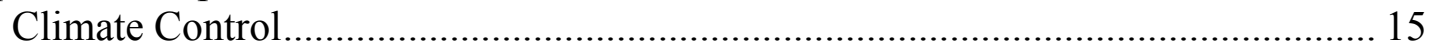

Electric Propulsion Motor Controls .................................................................. 15

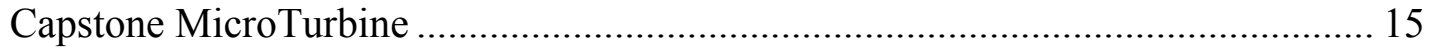

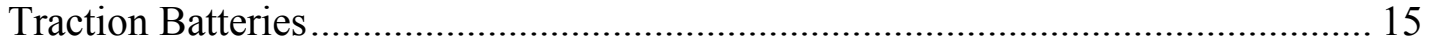

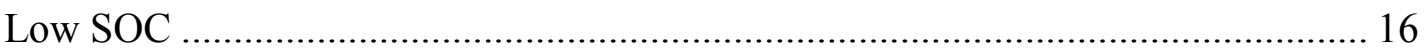

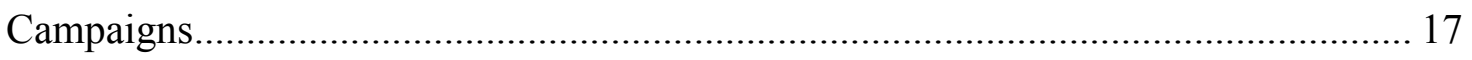

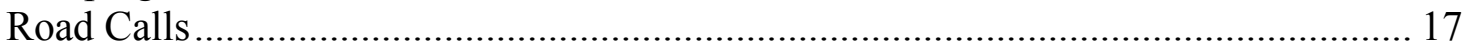

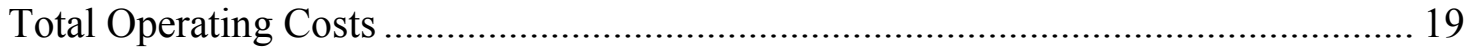

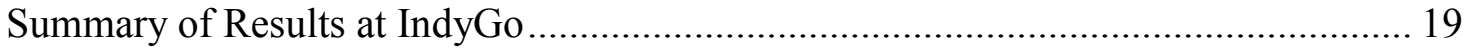

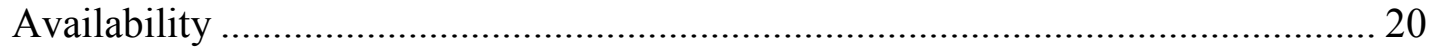

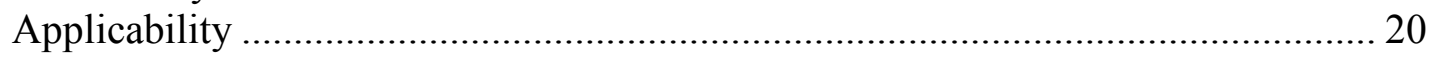

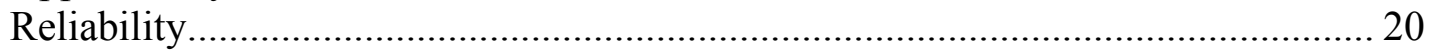

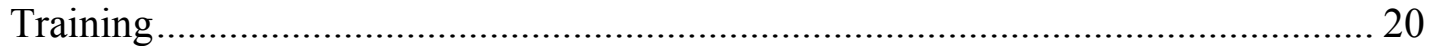

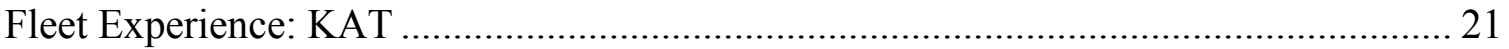

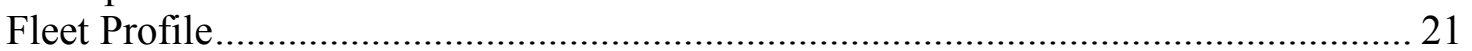

Implementation Experience ................................................................................ 22

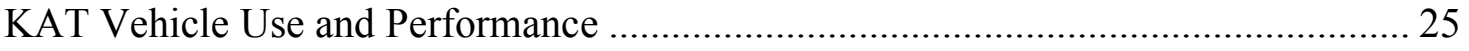

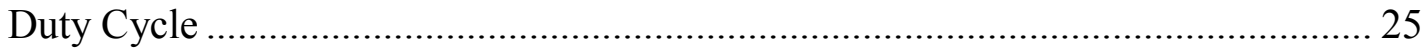

Fuel Economy Results ............................................................................... 26

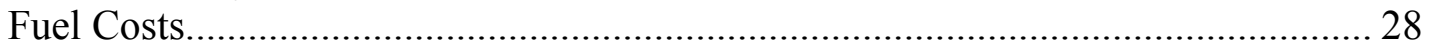




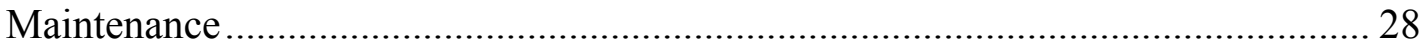

Specific Component Issues and Resolutions ………............................................... 31

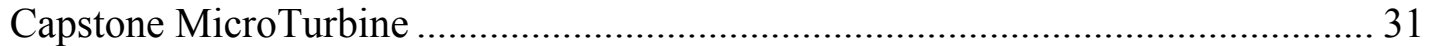

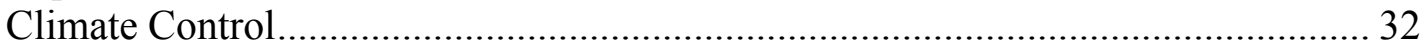

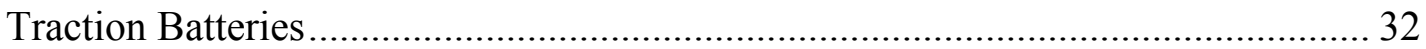

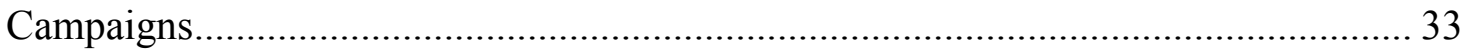

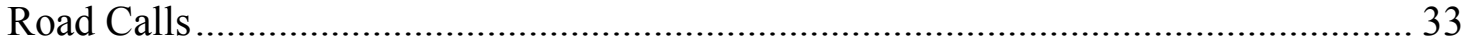

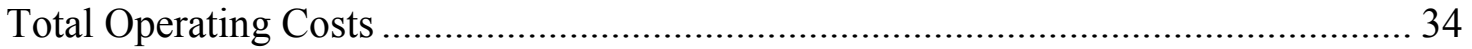

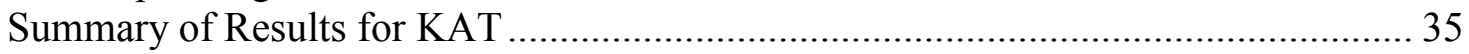

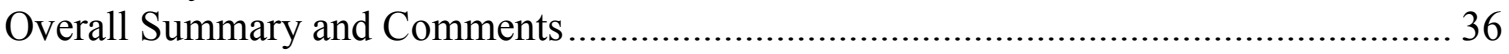

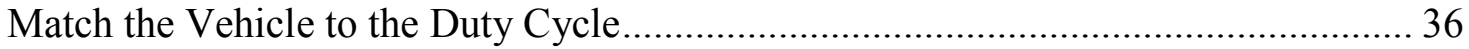

Train Drivers and Maintenance Personnel................................................................. 36

New Technology Is Still in Development................................................................. 37

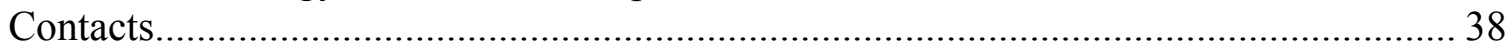

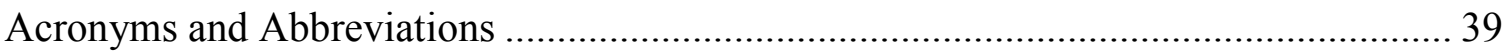

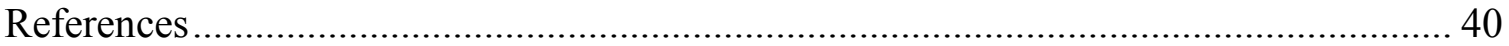

\section{List of Figures}

Figure 1. Ebus system block diagram (Source: Ebus)..................................................... 1

Figure 2. Schematic of Capstone MicroTurbine (Source: Capstone Turbine

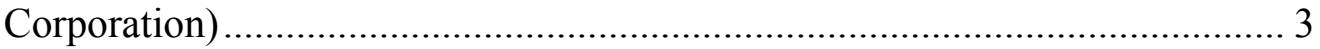

Figure 3. IndyGo's headquarters in Indianapolis, IN (Source: NREL)........................... 6

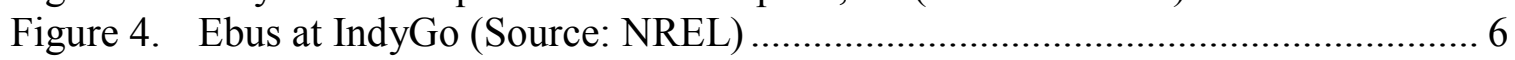

Figure 5. Battery tray for the electric propulsion system (Source: NREL) ..................... 7

Figure 6. Normal battery tray (left) and tray with a corroded cable (Source: NREL) .... 7

Figure 7. IndyGo's Blue Line route (Source: IndyGo) .................................................. 8

Figure 8. An IndyGo hybrid electric bus (Source: NREL) ........................................... 8

Figure 9. Cumulative miles traveled during the evaluation period at IndyGo ............... 10

Figure 10. IndyGo Fuel economy during the 6-month evaluation period......................... 11

Figure 11. IndyGo Cumulative maintenance costs per mile ……………........................ 13

Figure 12. Maintenance cost by vehicle system (Labor + Parts) ...................................... 13

Figure 13. Propulsion system maintenance costs (Labor + Parts) .................................. 14

Figure 14. Capstone MicroTurbine Assembly (Source: NREL) ...................................... 15

Figure 15. IndyGo Ebus at Charging Station (Source: NREL) ....................................... 16

Figure 16. IndyGo Route Stop (Source: NREL) ………………………………...... 17

Figure 17. Battery Charger Display (Source: NREL) .................................................. 18

Figure 18. IndyGo Cumulative miles between road calls .............................................. 19

Figure 19. KAT Maintenance Facility (Source: NREL) …………………….............. 22

Figure 20. KAT Ebus Trolley (Source: NREL Photo) .................................................... 23

Figure 21. Original and upgraded LPG fueling station ............................................... 23

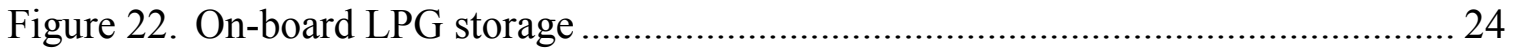

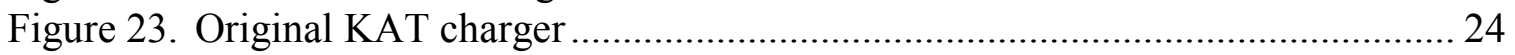

Figure 24. KAT Total mileage accumulation for the four Ebus trolleys ......................... 25

Figure 25. Red Line and other trolley routes in Knoxville ……………........................ 26

Figure 26. KAT Average fuel economy ................................................................ 28

Figure 27. KAT Cumulative maintenance costs per mile ............................................... 30 
Figure 28. KAT Maintenance costs by vehicle system (Labor + Parts) ....................... 31

Figure 29. KAT Propulsion system maintenance costs (Labor + Parts) ......................... 31

Figure 30. KAT Ebus Trolley traction battery pack (Source: NREL) ............................ 32

Figure 31. KAT Cumulative miles between road calls (MBRC) .................................... 34

Figure 32. KAT Cost per mile source breakdown.................................................. 35

\section{List of Tables}

Table 1. Ebus Series Hybrid Electric Propulsion System ..........................................2

Table 2. Capstone Model 330 Hybrid Electric Vehicle (HEV) MicroTurbine

Performance* .3

Table 3. Capstone MicroTurbine Emissions* .............................................................4

Table 4. Vehicle Systems Overview ........................................................................5

Table 5. IndyGo Hybrid-Electric Bus Duty Cycle.....................................................9

Table 6. IndyGo Fuel Economy Results (November 2004 through April 2005)..........11

Table 7. IndyGo Total Maintenance Cost Comparison (November 2004 through

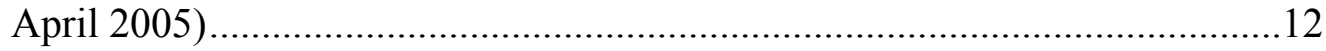

Table 8. IndyGo Propulsion System Costs (November 2004 to April 2005) ................14

Table 9. IndyGo Road Call Comparison (November 2004 to April 2005)...................18

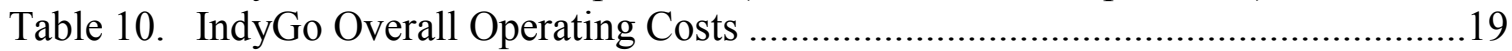

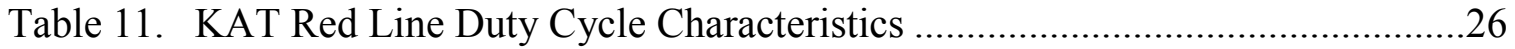

Table 12. KAT Fuel Economy Results for 6-Month Evaluation Period..........................27

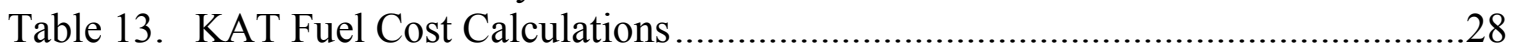

Table 14. KAT Total Maintenance Cost Comparison (December 2004 to May 2005)..29

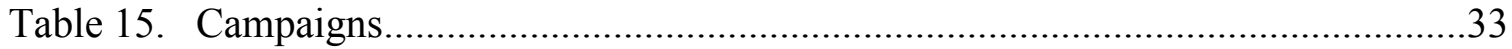

Table 16. KAT Road Call Comparison (December 2004 to May 2005) .......................34

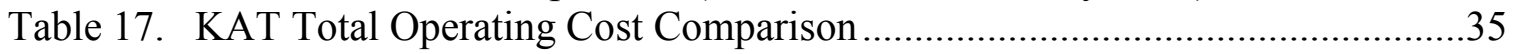




\section{Executive Summary}

The U.S. Department of Energy's (DOE) Advanced Vehicle Testing Activity (AVTA) provides unbiased evaluations on alternative fuel and advanced transportation technologies that reduce U.S. dependence on foreign oil while improving the nation's air quality. AVTA's role is to bridge the gap between research and development (R\&D) and the commercial availability of alternative fuels and advanced vehicle technologies. AVTA supports DOE's FreedomCAR \& Vehicle Technologies Program by examining market factors and customer requirements, evaluating the performance and durability of alternative fuel and advanced technology vehicles, and assessing the performance of these vehicles in fleet applications.

The Fleet Test \& Evaluation team at the National Renewable Energy Laboratory (NREL) supports AVTA by conducting medium- and heavy-duty vehicle evaluations. The team's tasks include selecting appropriate technologies to validate, identifying fleets to evaluate, designing test plans, gathering on-site data, preparing technical reports, and communicating results on its Web site and in print publications. One of the primary target audiences for AVTA evaluations is fleet operators who use or may consider using these advanced technologies. NREL has completed numerous light- and heavy-duty vehicle evaluations based on an established data collection protocol, known as the General Evaluation Plan, ${ }^{1}$ developed with and for DOE.

\section{Objectives}

This evaluation focuses on the demonstration of hybrid electric buses and trolleys produced by Ebus, Inc. (www.ebus.com), of Downey, California. Ebus manufactures 22foot buses with a variety of optional powertrains and exterior designs. The vehicles come with battery electric and hybrid electric powertrain options, and purchasers can choose either conventional bus or antique-trolley-style exteriors. The Indianapolis Transportation Corporation (IndyGo) and Knoxville Area Transit (KAT) participated in a demonstration of the Ebus vehicles. Each fleet chose hybrid electric powertrains but selected different exterior designs and fuels. These vehicles were placed in revenue transit service to provide the following:

- Credible data and evaluation results

- Results that show progress and experience in using hybrid electric buses in transit service

- Results from multiple operating experiences and different transit agencies.

\section{Technology}

Ebus's hybrid electric vehicles are propelled by battery-powered electric motors that supply power to the wheels. Two nickel-cadmium (NiCd) traction battery packs are kept within a prescribed range of state of charge (SOC) by a generator or powerplant. The battery packs operate at $60 \%$ to $80 \%$ SOC and allow for the use of regenerative braking, which recovers energy from the braking system. The hybrid system uses a $30 \mathrm{~kW}$

\footnotetext{
${ }^{1}$ Available on the Web at www.nrel.gov/vehiclesandfuels/fleettest/pdfs/32392.pdf.
} 
Capstone MicroTurbine ${ }^{\mathrm{TM}}$ (www.capstoneturbine.com) auxiliary power unit (APU) as a primary powerplant. Onboard fuel storage supplies the APU. The APU can operate on several fuels, including compressed natural gas (CNG), liquefied petroleum gas (LPG), and diesel fuel. The hybrids are primarily designed as a charge-sustaining series hybrid, meaning that the batteries have power as long as the APU has fuel. The hybrids can be plugged into charging systems overnight to bring the batteries up to a $100 \%$ SOC for the morning pullout. Used in this way, they initially operate as charge-depleting series hybrids until SOC reduction activates the APU, and operation begins in charge-sustaining mode.

\section{Evaluation Methods}

Data were collected and evaluated for five diesel-fueled buses at IndyGo and four LPGfueled trolleys at KAT. Data included the following:

- Fuel consumption by vehicle

- Mileage data by vehicle

- Preventive maintenance work orders, labor events, and parts lists

- Records of unscheduled maintenance, such as road calls.

Although there were some attempts to do so, data were not collected for energy gains due to opportunity charging of the vehicles' traction battery packs. In addition, "selfcharging" (discussed later) and its effect on fuel economy were not quantified. Therefore, fuel economy calculations are based solely upon miles driven and liquid fuel volumes recorded.

\section{Results}

The following is a summary of the project results:

- IndyGo and KAT successfully deployed diesel- and LPG-fueled Ebus hybrids in revenue service, collecting six months of performance and operating data for analysis.

- Both agencies designed new routes for the demonstration vehicles. Route duty cycles differed between the fleets.

\section{IndyGo}

- IndyGo observed an average fuel economy of $4.37 \mathrm{mpg}$.

- IndyGo observed a maintenance cost per mile of $\$ 0.66$, a fuel cost per mile of $\$ 0.37$, and a total operating cost per mile of $\$ 1.03$.

- IndyGo observed a hybrid propulsion maintenance cost of $\$ 0.46$ per mile.

- IndyGo used the Ebus hybrids on a 12-hour duty cycle in a downtown circulator route. Although the buses exhibited lower than expected availability, they were considered successful in terms of cost per mile and fuel economy. 


\section{KAT}

- KAT observed an average fuel economy of $3.22 \mathrm{mpg}$ (diesel equivalent gallons for LPG use).

- KAT observed a maintenance cost per mile of $\$ 0.62$, a fuel cost per mile of $\$ 0.35$, and a total operating cost per mile of $\$ 0.97$.

- KAT observed a hybrid propulsion maintenance cost of \$0.12 per mile.

- KAT used the Ebus hybrids on more demanding terrain than IndyGO did, but for shorter periods of time each day. The agency experienced fewer hybrid systemrelated problems than IndyGo did.

\section{Both Fleets}

- For both fleets, there were road calls and maintenance events characterized by turbine fault codes and reports of low SOC. These events were caused by drivers accidentally shutting down turbines and by an on-road failure of the turbine to ignite. The events were more prevalent in IndyGo's experience, because the ignitability of diesel fuel is lower than that of LPG. Corrective actions were taken both by Ebus and the fleet maintenance personnel.

- Both fleets "warmed-up" their vehicles for 30 to 60 minutes before going on their routes. The fleets felt that they experienced fewer road calls and maintenance problems using this practice.

- Each fleet cited matching vehicles to an appropriate duty cycle and training drivers and maintenance personnel adequately as important lessons learned. 


\section{Overview: Ebus Hybrid Buses and Trolleys}

This report focuses on the evaluation of hybrid electric buses and trolleys produced by Ebus, Inc., and demonstrated by the Indianapolis Transportation Corporation (IndyGo) and Knoxville Area Transit (KAT).

Ebus vehicles feature a series hybrid architecture, which means the vehicles' auxiliary power unit (APU) is used with a generator to produce electricity for the battery pack and electric motor. In series hybrid electric systems, there is no mechanical connection between the APU and the wheels. Therefore, to drive the wheels, all motive power is transferred from chemical energy to mechanical energy, from mechanical energy to electrical energy, and from electrical energy back to mechanical energy.

The Ebus hybrid electric system propels the vehicle using an electric motor powered by the traction battery packs. The two traction battery packs feature nickel-cadmium $(\mathrm{NiCd})$ batteries recharged by a low-emission Capstone MicroTurbine APU. A digital power controller monitors and controls the recharging of the batteries by the MicroTurbine. This system is chargesustaining, meaning that the batteries will have energy as long as the APU has fuel. Figure 1 illustrates the Ebus system.

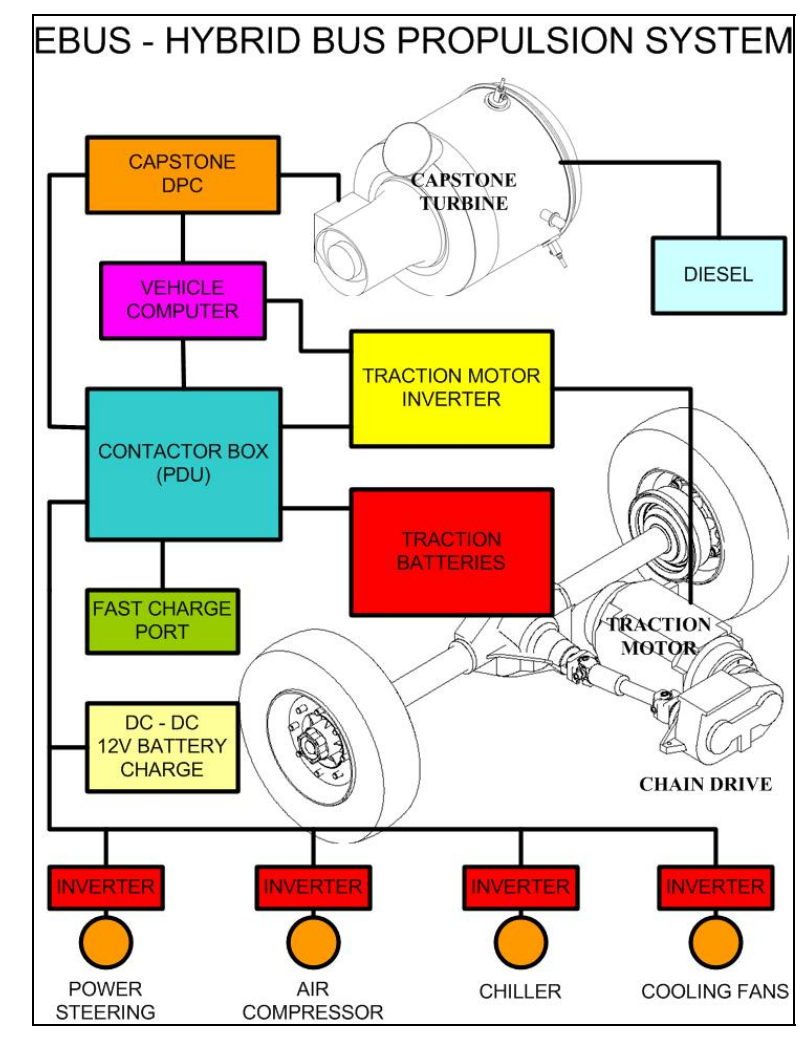

Figure 1. Ebus system block diagram (Source: Ebus)

The hybrid propulsion design also incorporates regenerative braking, which provides additional energy to recharge the traction battery packs. In this system, the electric motor that drives the 
vehicle becomes a generator during deceleration, and the energy produced from deceleration is stored in the batteries. This technology is particularly effective for transit applications on routes featuring stop-and-go traffic. A toggle switch located on the dashboard console activates or deactivates regenerative braking during driving. Winter driving conditions occasionally warrant predictable conventional braking; therefore, IndyGo requested simple deactivation of regenerative braking. When the vehicle is not in operation, it can be plugged into a fast-charging station that "tops off" the batteries in approximately 1 hour.

Ebus offers this hybrid electric system for a range of fuels, including diesel, liquefied petroleum gas (LPG), and compressed natural gas (CNG). Onboard liquid fuel capacity is 50 gallons. Table 1 presents some general characteristics of the hybrid electric propulsion system.

Table 1. Ebus Series Hybrid Electric Propulsion System

\begin{tabular}{|l|l|}
\hline APU & Capstone MicroTurbine Model 330 \\
\hline Motor & Reliance AC Induction, air-cooled \\
\hline Energy Storage & $\begin{array}{l}\text { 48 NiCd, liquid-cooled, "fast charge" batteries, 288 V } \\
\text { total-manufactured by Saft }\end{array}$ \\
\hline Opportunity Charging & SAE J-2293 Fast Charging \\
\hline Charge Sustaining & Yes \\
\hline Regenerative Braking & Yes \\
\hline
\end{tabular}

\section{Capstone MicroTurbine APU}

The Capstone MicroTurbine system has several components. These include a compressor, recuperator, combustor, turbine, and permanent magnet generator.

The combustion process begins as air enters the system through an intake, passing and cooling the generator. This approach to heat transfer eliminates the need to liquid-cool the system. Intake air is compressed and injected into the recuperator, where it is heated by turbine exhaust. Fuel enters the system through an injection port and is mixed with the heated compressed air. An ignition mechanism causes the air/fuel mixture to burn in the combustion chamber and, during this expansion through the turbine, this provides rotational power. The rotating components, which can reach 96,000 rpm, are mounted on a single shaft supported by low-maintenance air bearings.

This advanced combustion process results in a low-emission exhaust stream, which exits the combustion chamber. The final result is variable voltage, variable frequency, alternating current (AC) power, which is converted to programmable direct current (DC) power by on-board power electronics. Table 2 presents Capstone MicroTurbine performance specifications, and Figure 2 is a schematic of the components. 
Table 2. Capstone Model 330 Hybrid Electric Vehicle (HEV) MicroTurbine Performance*

\begin{tabular}{|l|c|c|c|}
\hline Fuel & CNG $(55 \mathrm{psig})$ & LPG $(55 \mathrm{psig})$ & Diesel $(5 \mathrm{psig})$ \\
\hline Overhaul Life & $20,000 \mathrm{hr}$ & $20,000 \mathrm{hr}$ & $20,000 \mathrm{hr}$ \\
\hline Full-Load Power & $30 \mathrm{~kW}$ net $(+/-1 \mathrm{~kW})$ & $30 \mathrm{~kW}$ net $(+/-1 \mathrm{~kW})$ & $29 \mathrm{~kW}$ net $(+/-1 \mathrm{~kW})$ \\
\hline Peak Efficiency $\left(\mathrm{LHV}^{* *}\right)$ & $27 \%(+/-2 \%)$ & $27 \%(+/-2 \%)$ & $26 \%(+/-2 \%)$ \\
\hline Fuel Flow ${ }^{* * *}$ & $18.7 \mathrm{lb} / \mathrm{hr}, 8.5 \mathrm{~kg} / \mathrm{hr}$ & $19.0 \mathrm{lb} / \mathrm{hr}, 8.6 \mathrm{~kg} / \mathrm{hr}$ & $21.9 \mathrm{lb} / \mathrm{hr}, 10.0 \mathrm{~kg} / \mathrm{hr}$ \\
\hline Fuel Flow, Equivalent & $\mathrm{N} / \mathrm{A}$ & $4.5 \mathrm{gal} / \mathrm{hr}, 17.2 \mathrm{l} / \mathrm{hr}$ & $2.9 \mathrm{gal} / \mathrm{hr}, 11.0 \mathrm{l} / \mathrm{hr}$ \\
\hline Exhaust Gas Temperature & $500^{\circ} \mathrm{F}, 261^{\circ} \mathrm{C}$ & $500^{\circ} \mathrm{F}, 261^{\circ} \mathrm{C}$ & $500^{\circ} \mathrm{F}, 261^{\circ} \mathrm{C}$ \\
\hline Output Voltage & $250-700 \mathrm{VDC}$ & $250-700 \mathrm{VDC}$ & $250-700 \mathrm{VDC}$ \\
\hline
\end{tabular}

*Source: Capstone Turbine Corporation

** Lower Heating Value

${ }^{* * *}$ Rated at LHV: 20,167 Btu/lbm (CNG), 19,916 Btu/lbm (LPG), 18,250 Btu/lbm (diesel)

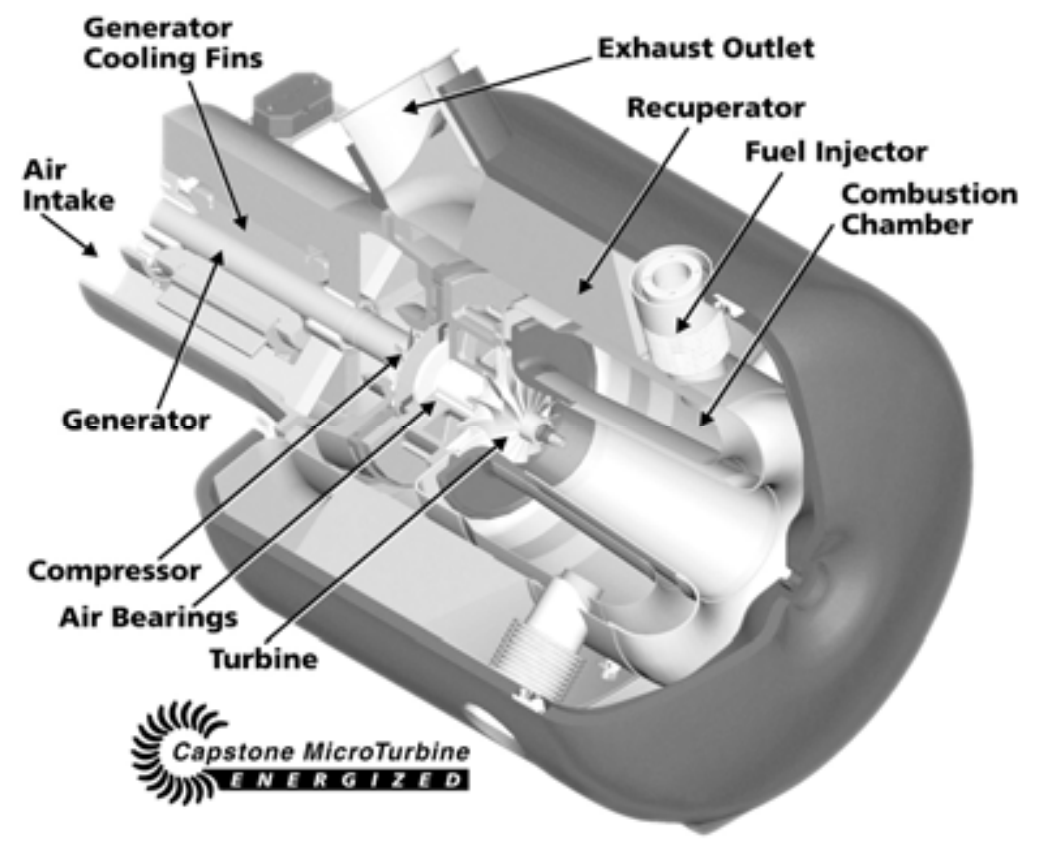

Figure 2. Schematic of Capstone MicroTurbine (Source: Capstone Turbine Corporation)

\section{Traction Batteries}

Energy storage for propulsion is accomplished using 48 liquid-cooled NiCd batteries.

Manufactured by Saft, these batteries supply $288 \mathrm{~V}$ at a capacity of 200 ampere-hours. The battery pack is located under the floor of the vehicle, in front of the rear wheels. To improve the battery pack's performance and extend its life, Ebus retrofitted the battery tray with a liquidcooling system. The liquid used to cool the batteries is a 50/50 mixture of distilled water and Dexcool, an ethylene-glycol-based antifreeze.

The traction batteries supply power to a single AC induction propulsion motor manufactured by Reliance Electrical Industrial Company. This motor provides driveshaft torque, which propels the vehicle. While the bus is being driven, the battery pack maintains a $60 \%$ to $80 \%$ SOC rating. When the SOC falls below $60 \%$, the turbine activates, providing charge to the batteries and elevating the SOC. The turbine cycles off when the SOC is restored to $80 \%$. 
When garaged at night, the Ebus vehicles are plugged into a battery charging system to elevate the SOC to $100 \%$. Opportunity charging of the batteries extends the vehicle's electric-only range before it begins burning fuel in the APU. This system is consistent with SAE J-2293, which establishes requirements for electric vehicles (EV) and the off-board supply equipment used to transfer electrical energy to an EV from an electric utility power system in North America.

\section{Emissions}

The Ebus hybrid electric vehicles (HEV) emit lower amounts of four criteria air pollutants, in comparison to emissions from conventional diesel-fueled internal combustion engines. Table 3 summarizes the results of HEV emission cycle testing on Capstone's model $330 \mathrm{HEV}$ MicroTurbine. The test is certified by the California Air Resources Board. Reported measurements of hydrocarbons ( $\mathrm{HC}$ ) and carbon monoxide (CO) for a diesel-fueled MicroTurbine are from Ebus internal test results, measured in accordance with California Air Resources Board (CARB) protocols.

Table 3. Capstone MicroTurbine Emissions*

\begin{tabular}{|l|r|r|r|}
\hline Emissions & \multicolumn{1}{|c|}{ CNG } & \multicolumn{1}{c|}{ LPG } & \multicolumn{1}{c|}{ Diesel } \\
\hline NOx ${ }^{* *}(\mathrm{~g} / \mathrm{bhp}-\mathrm{hr})$ & 0.26 & 0.53 & 0.70 \\
\hline $\mathrm{HC}(\mathrm{g} / \mathrm{bhp}-\mathrm{hr})$ & 0.42 & 0.42 & $0.30^{* * *}$ \\
\hline $\mathrm{CO}(\mathrm{g} / \mathrm{bhp}-\mathrm{hr})$ & 0.41 & 0.18 & $0.40^{* * *}$ \\
\hline $\mathrm{PM}^{* *}(\mathrm{~g} / \mathrm{bhp}-\mathrm{hr})$ & 0.004 & 0.004 & 0.01 \\
\hline
\end{tabular}

*Source: www.capstoneturbine.com

${ }^{* *} \mathrm{NOx}$ is oxides of nitrogen; PM is particulate matter; bhp is brake horsepower.

${ }^{* * *}$ Ebus internal test results

\section{Durability}

An Ebus trolley powered by a diesel-fueled Capstone MicroTurbine APU was submitted for a 7year/200,000 mile Surface Transportation and Uniform Relocation Assistance Act (STURAA) test at the Pennsylvania Transportation Institute's Bus Testing and Research Center in Altoona, Pennsylvania. Any bus manufacturer who intends to sell buses in the United States must submit its products for this required testing. This particular testing began in October 2001 and was completed in February 2002.

\section{Project Design and Data Collection}

The National Renewable Energy Laboratory's (NREL) evaluation of the five diesel hybrid buses at IndyGo and four LPG hybrid trolleys at KAT began in 2004. The data collection and evaluation protocol used was developed by NREL and the U.S. Department of Energy (DOE). A limited evaluation was carried out at the two sites because of the vehicles' application and stage of development. This limited evaluation focuses on 6 months of full operation of the test vehicles. The information collected includes operational data such as vehicle use, fuel consumption, and maintenance performed as well as descriptions of the fleets' experience with these vehicles.

Data for as many as 12 months were collected from the two evaluation sites. After analyzing the collected data, researchers identified a "clean-point" in the data for each fleet. The clean-point is typically the point at which a fleet clears the initial hurdles associated with implementing new 
vehicles and technologies. After that point, a 6-month data collection period was identified for each fleet, and performance and cost calculations were based on that data collection period.

The objective of this evaluation is to provide credible data and results in a case study that will help assess the progress of hybrid electric technologies, based on the experience of two fleets that employed slightly different versions of the Ebus technology (see Table 4).

Technology applications and utilization varied between the two fleets. Therefore, given the differences in fuels used and duty cycles, a direct comparison of the fleets is not possible. NREL evaluations typically compare HEVs with conventional technology vehicles having the same duty cycle. However, neither fleet in this study included comparable conventional vehicles that would permit a baseline comparison. The 6-month evaluation period also differs slightly for each fleet because they received their Ebus vehicles and cleared initial implementation hurdles at different times. The evaluation period for IndyGo was November 2004 to April 2005; for KAT, this period was December 2004 to May 2005.

Table 4. Vehicle Systems Overview

\begin{tabular}{|l|c|c|}
\hline Fleet & KAT & IndyGo \\
\hline Vehicles Purchased & Four & Five \\
\hline Model & Trolley & Bus \\
\hline Model Year & 2003 & 2003 \\
\hline Fuel & LPG & No. 2 Diesel \\
\hline Fuel Capacity & $50 \mathrm{gal}$ & $50 \mathrm{gal}$ \\
\hline Vehicle Cost & $\$ 280,000$ & $\$ 280,000$ \\
\hline Length/Width/Height & $22 \mathrm{ft} / 92 \mathrm{in} / 120 \mathrm{in}$ & $22 \mathrm{ft} / 92 \mathrm{in} / 103 \mathrm{in}$ \\
\hline GWWR*/Curb Weight & $19,500 / 14,500 \mathrm{lb}$ & $19,500 / 14,500 \mathrm{lb}$ \\
\hline Seated Passenger Capacity & 22 (one wheelchair) & 22 (one wheelchair) \\
\hline Total Passenger Capacity & 29 (seven standing) & 29 (seven standing) \\
\hline Service & Knoxville, Tennessee & Indianapolis, Indiana \\
\hline
\end{tabular}

\section{Fleet Experience: IndyGo}

\section{Fleet Profile}

Indianapolis Public Transportation Corporation, or IndyGo, offers commuter services to the City of Indianapolis and Marion County, Indiana (www.indygo.net). Operating 28 fixed and demand response routes, IndyGo has 228 vehicles, including paratransit vehicles. In 2003, IndyGo carried nearly 11 million passengers and traveled approximately 9 million miles.

IndyGo has 144 Gillig buses at its facilities at the edge of downtown Indianapolis. All operations - including scheduling, maintenance, public relations, and some training - are conducted at this central facility. Most vehicle maintenance is also done inside this facility, which has enough garage space for all the buses to be parked there at one time. 


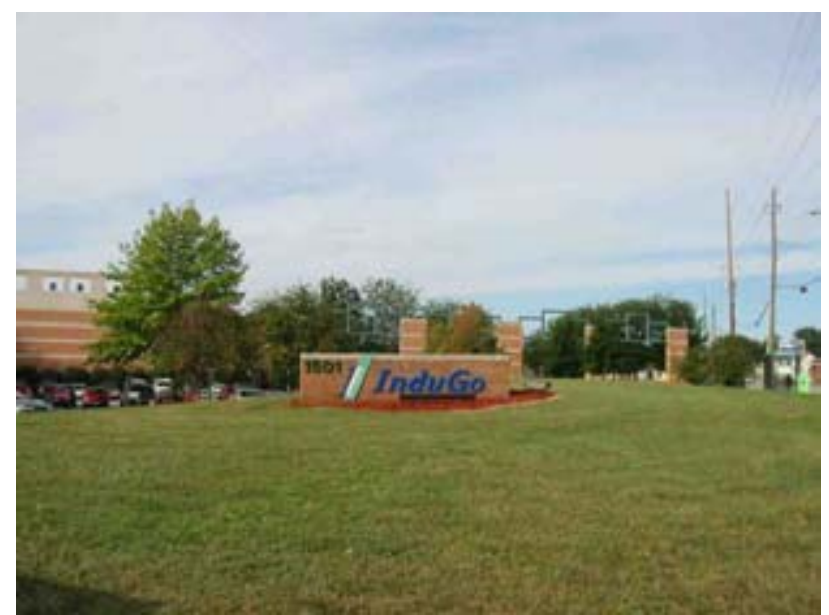

Figure 3. IndyGo's headquarters in Indianapolis, IN (Source: NREL)

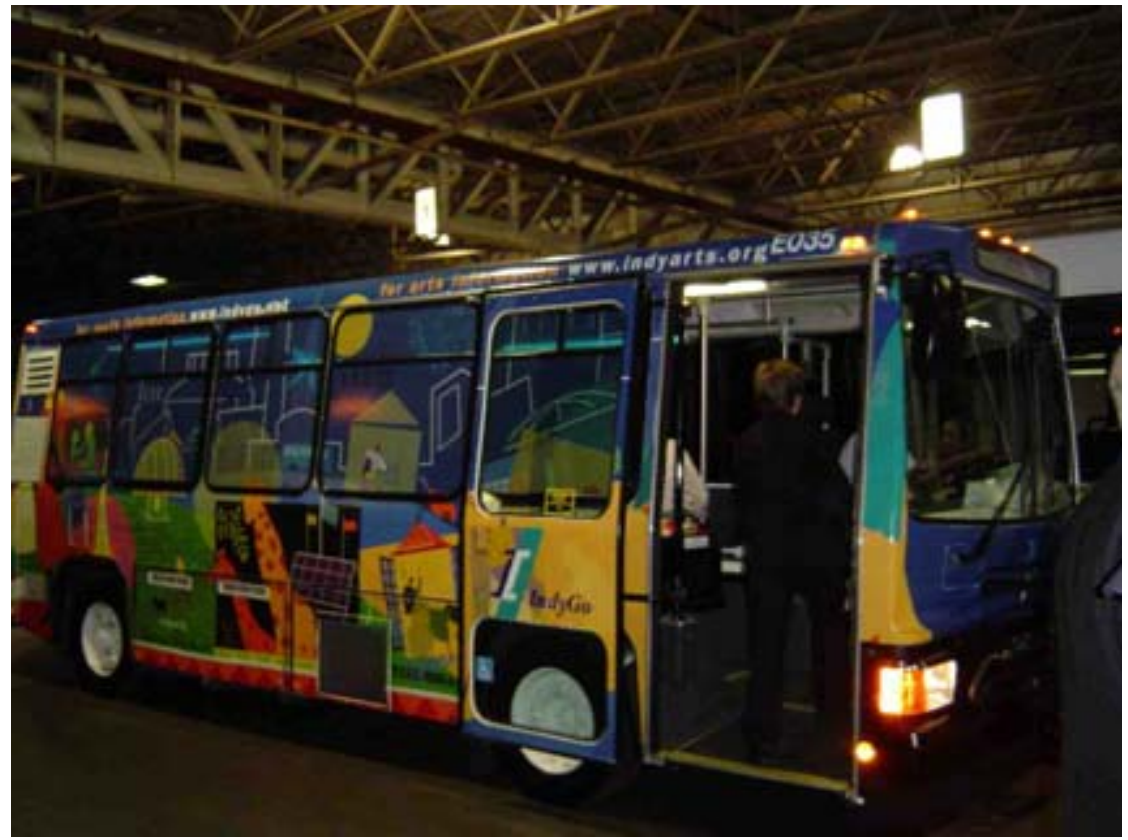

Figure 4. Ebus at IndyGo (Source: NREL)

\section{Implementation Experience}

As part of a technical development effort, in August 2003 IndyGo received five hybrid electric buses that were purchased from Ebus. Product and market availability were the deciding factors in purchasing the EBus buses. Negotiations between the two companies began in spring 2003. The procurement was intended to move IndyGo forward with new technology, enhance its image, and attract new events to the city. In addition, the buses would benefit the city by reducing air and noise pollution. Funding for the five buses came in part from The City of Indianapolis and in part through a Congestion Mitigation Air Quality (CMAQ) grant obtained by the Indiana Department of Transportation and IndyGo. The goal of the CMAQ program is to reduce congestion and emissions in designated nonattainment air quality areas.

IndyGo's Ebus diesel hybrid electric buses went in service in August 2003 and remained in service until early February 2004, when a setback occurred. Salt applied to the snow-covered 
roads of Indianapolis began to corrode a cable and fuse that were exposed through the battery tray of the electric system, which is located along the lower part of the bus, as shown in Figure 5. The corroded cable caused a high-voltage source to ignite while the bus was parked in the bus garage overnight on Friday, February 6, 2004 (see Figure 6). The fire spread, damaging two of the hybrid-electric buses, two chargers, and part of the garage. There were no injuries.

Ebus replaced the damaged bus approximately 5 to 6 months after the incident and repaired the other bus. In addition, one of IndyGo's battery chargers had to be repaired and one had to be purchased because of the fire damage. To prevent further incidents, Ebus enclosed the highvoltage cable that had run through the tray and exposed a fuse. This change was made to all the vehicles ordered that had this system. The fire slowed down the implementation process for IndyGo and this evaluation, but no further problems occurred after the changes were completed.

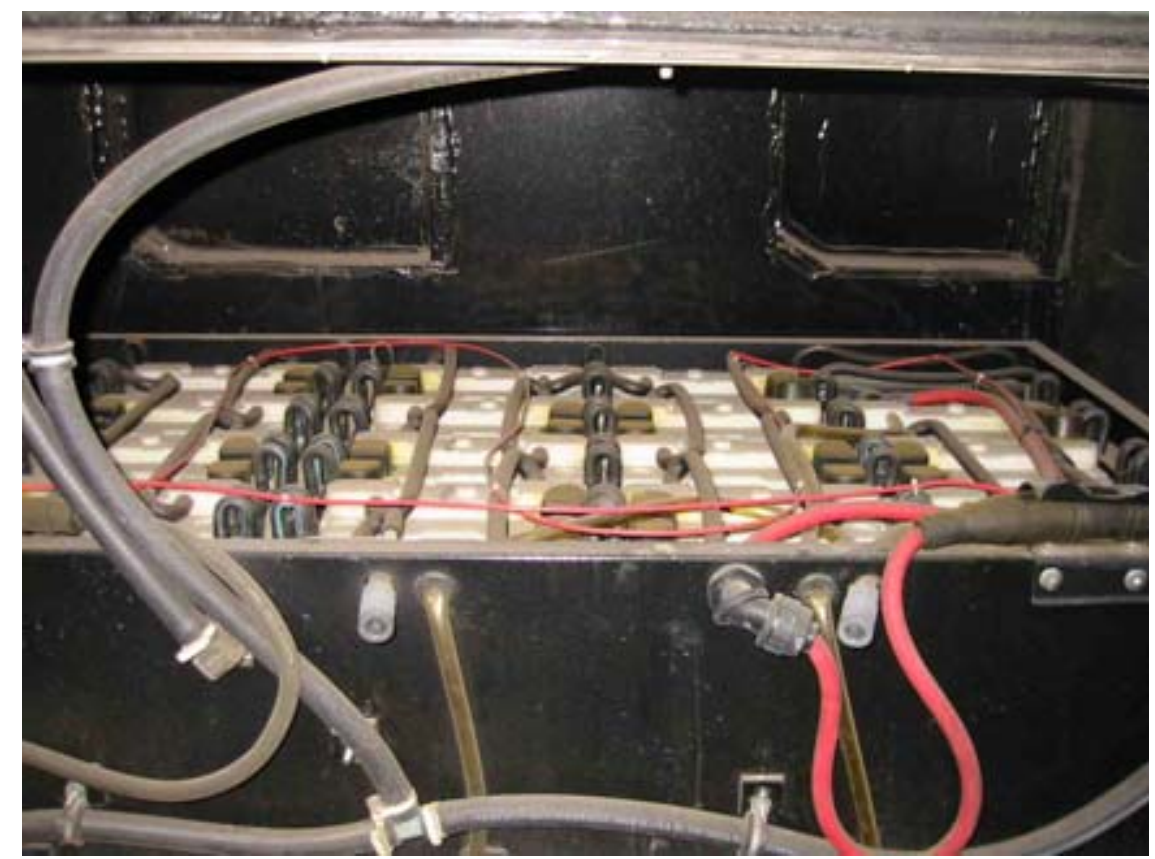

Figure 5. Battery tray for the electric propulsion system (Source: NREL)

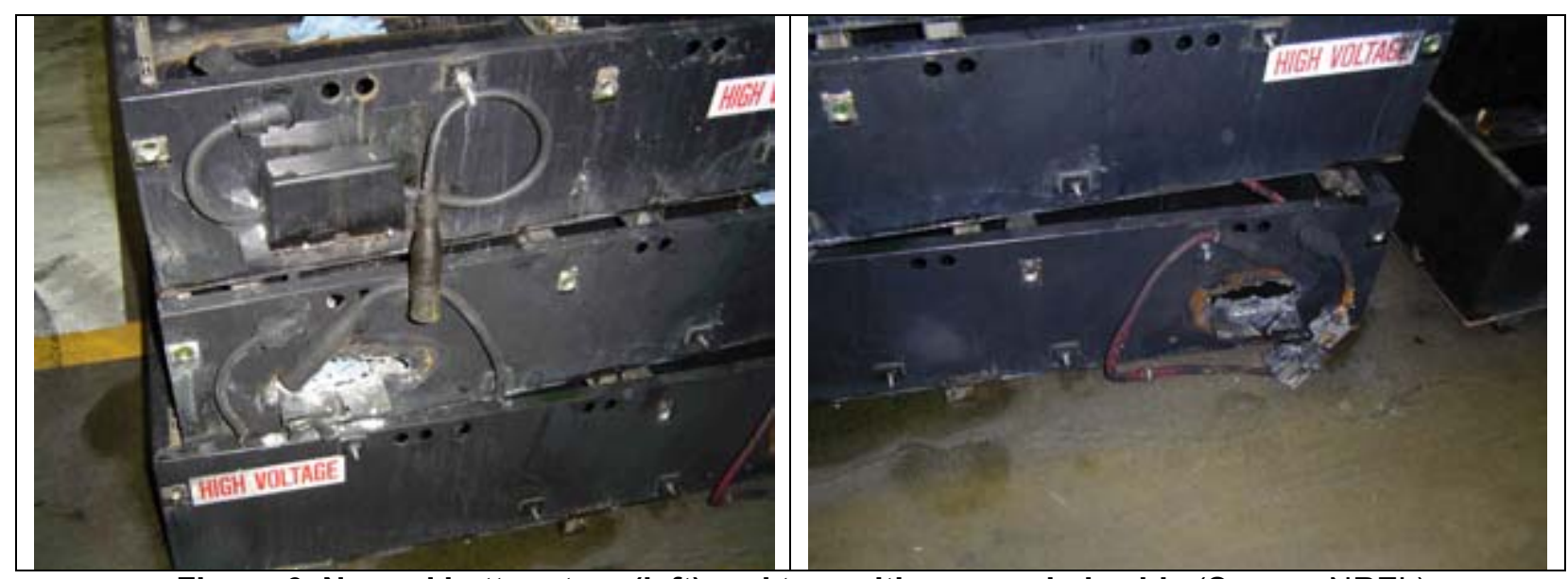

Figure 6. Normal battery tray (left) and tray with a corroded cable (Source: NREL) 


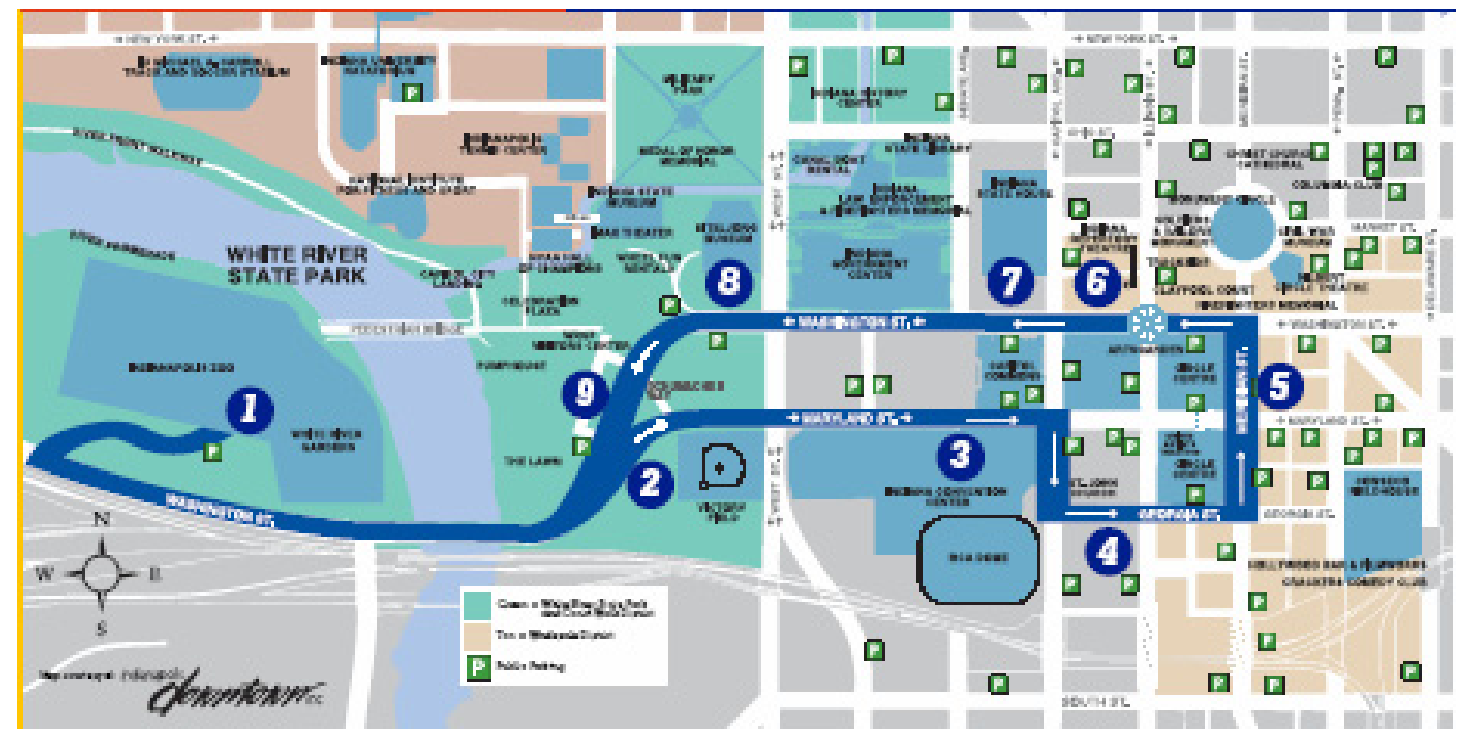

Figure 7. IndyGo's Blue Line route (Source: IndyGo)

\section{IndyGo Vehicle Use and Performance}

\section{Duty Cycle}

The hybrid electric buses operate on IndyGo's Blue Line, a circulator route connecting several attractions in downtown Indianapolis. The route is a 4.3-mile loop that begins and ends at the Indianapolis Zoo. The route makes seven additional stops at area attractions such as Victory Field, the Eitljorg Museum of American Indians and Western Art, the Convention Center, and the Circle Center Mall. Figure 7 shows this route, which was designed in August 2003 specifically for the hybrid electric buses. Data for conventional diesel buses operating on a similar route were not available to provide a baseline comparison for this evaluation.

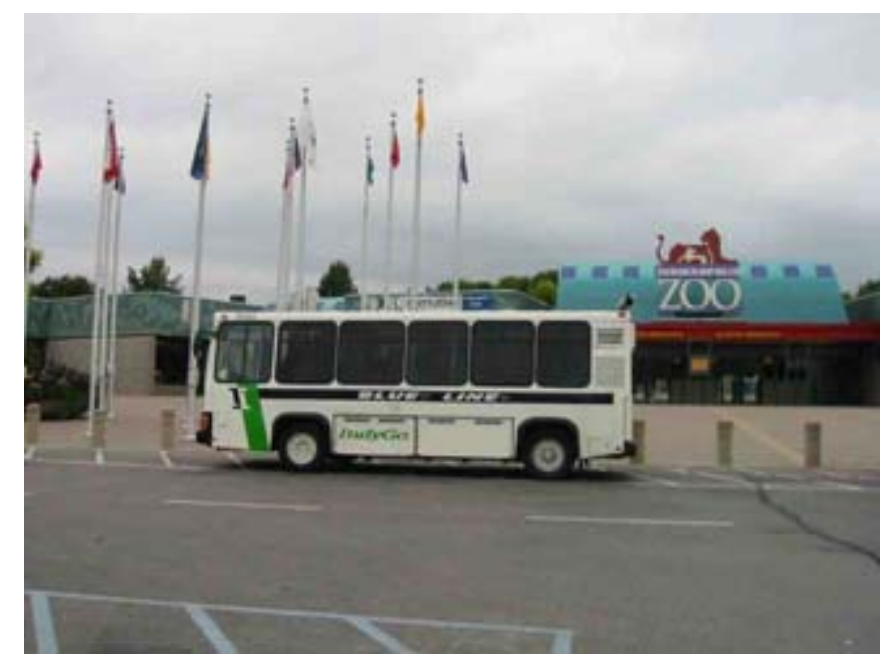

Figure 8. An IndyGo hybrid electric bus (Source: NREL)

Three of IndyGo's five hybrid electric buses were originally scheduled to be assigned to the Blue Line route each day for 7 days a week. The buses circulate the route between 9 a.m. and 9 p.m.; a 
bus arrives at each stop in 10-minute intervals. Each of the three buses is scheduled to circulate the 4.3-mile loop 24 times a day with a 9-minute layover at the zoo ("catch-up time") between runs. On this route, the average speed of a bus is $12.3 \mathrm{mph}$, and the maximum speed is 35 to 40 mph (see also Table 5).

Table 5. IndyGo Hybrid-Electric Bus Duty Cycle

\begin{tabular}{|l|l|}
\hline Terrain & Flat, light city driving \\
\hline Climate (Annual, 2003) & \\
Low Temperature & $-9^{\circ} \mathrm{F}$ \\
High Temperature & $93^{\circ} \mathrm{F}$ \\
Precipitation & $52.6 \mathrm{in.}$ \\
Sleet or Snow & 44.1 in. \\
\hline Route & Blue Line (90) \\
\hline Loop Distance & 4.3 miles \\
\hline Total Distance Traveled per Day & 313.9 total miles for all three buses \\
\hline & 21 minutes, with a 9-minute layover \\
\hline Time per Loop & between loops \\
\hline Operating Hours & 9 a.m. to 9 p.m. \\
\hline Average Speed & $12.3 \mathrm{mph}$ \\
\hline Maximum Speed & $35 \mathrm{mph}$ to $40 \mathrm{mph}$ \\
\hline
\end{tabular}

The Blue Line is characterized by light city driving on flat terrain with marked seasonal differences - hot and humid in summer and cold and snowy in winter. Buses on this route encounter considerable stop-and-go traffic, which helps to recharge HEV battery packs. However, the flat terrain of downtown Indianapolis is not optimal for a regenerative braking system. A more hilly terrain allows a regenerative braking system to capture additional energy and transfer it to the battery pack when a vehicle is decelerating on an incline.

In late spring 2005, the Blue Line was modified to assign two buses rather than three to this route, because three of the five HEV buses were often in the garage for repairs. IndyGo attempted to maintain a technician-to-bus ratio of 1:5 or less but often needed 2:5. The overall maintenance requirement was augmented by considerable support from Ebus. However, it often took a month to receive an ordered part needed to repair a bus, and this caused vehicles to be unavailable for service for extended periods of time.

In spite of their reduced availability, there was a reasonably steady upward trend in the number of miles that the hybrid electric buses accumulated over the evaluation period. Figure 9 shows this upward trend, during which the hybrid electric buses logged approximately 20,000 miles of revenue service by April 2005. 


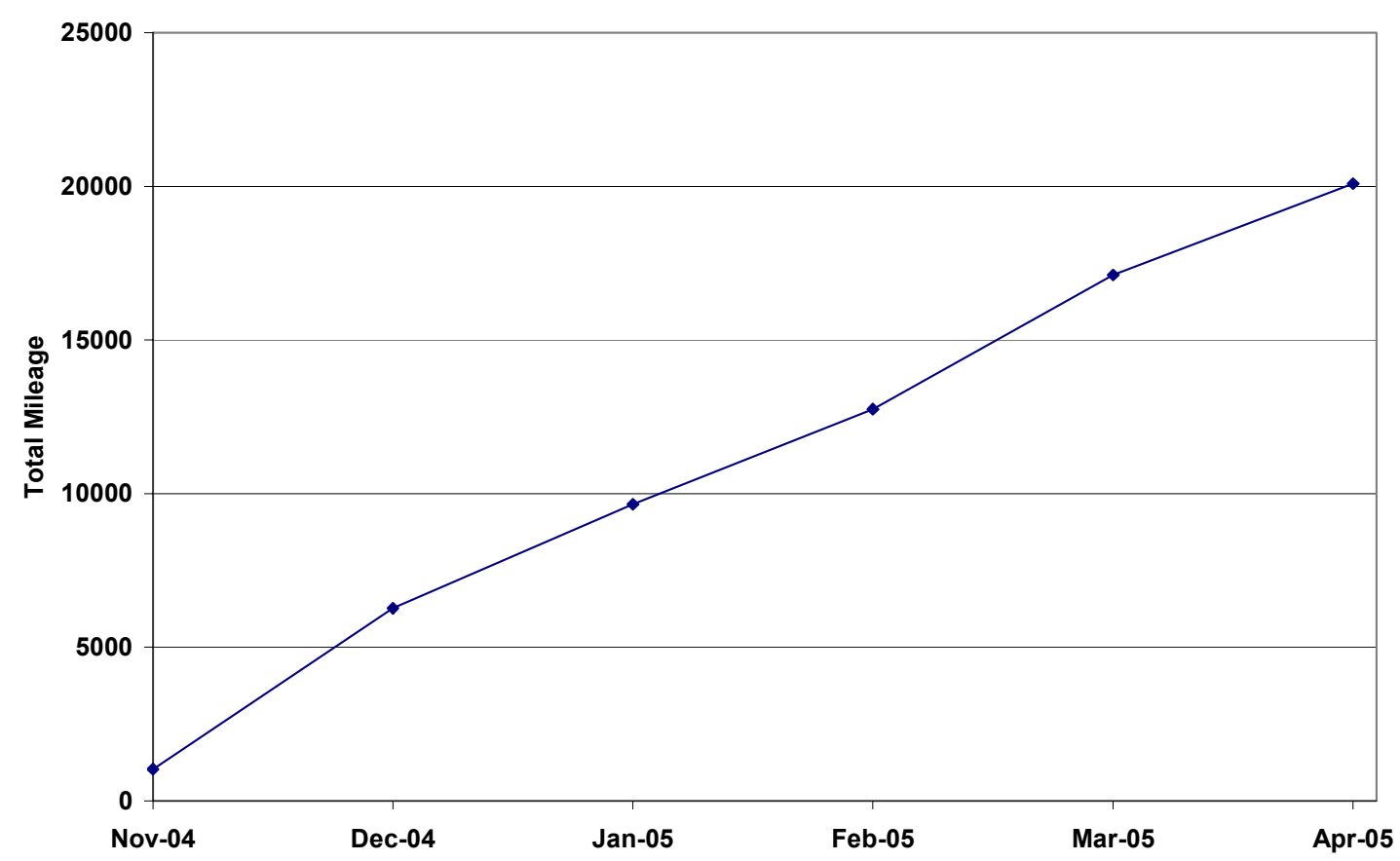

Figure 9. Cumulative miles traveled during the evaluation period at IndyGo

\section{Fuel Economy Results}

IndyGo's hybrid electric buses use diesel fuel to start and maintain the operation of the MicroTurbine. As noted earlier, fuel economy calculations are based solely upon miles driven and liquid fuel volumes recorded. The effects of opportunity charging and self-charging of the traction battery packs were not quantified and are not considered. A fuel economy value based on miles per gallon of diesel fuel used in each of the five buses over a 6-month evaluation period is provided in Table 6 .

Between November 2004 and April 2005, the average fuel economy of the buses was $4.37 \mathrm{mpg}$. During this time, bus E032 had a much lower average fuel economy than that of the other four buses. This can be attributed to at least two things: this bus spent less time overall running the route and maintained less complete fueling records than the other buses did. Figure 10 summarizes the fuel economy of the five buses over the same 6-month evaluation period. A total of 20,087 revenue miles were accumulated during the evaluation period, but the mileage accrual was not spread evenly across all five buses. In some months, a bus would not run at all, which suggests that it might have been waiting for parts or had become the "spare parts" bus during that time. This is explained further in the section on maintenance. 
Table 6. IndyGo Fuel Economy Results (November 2004 through April 2005)

\begin{tabular}{|c|r|r|r|}
\hline Bus & $\begin{array}{c}\text { Mileage } \\
\text { Used }\end{array}$ & \multicolumn{1}{c|}{$\begin{array}{c}\text { Diesel } \\
\text { Consumed } \\
\text { (gallons) }\end{array}$} & $\begin{array}{c}\text { Fuel Economy } \\
(\mathrm{mpg})\end{array}$ \\
\hline $\mathrm{E} 031$ & 4,145 & 888 & 4.67 \\
\hline $\mathrm{E} 032$ & 1,883 & 512 & 3.68 \\
\hline $\mathrm{E} 033$ & 5,286 & 1,080 & 4.89 \\
\hline $\mathrm{E} 034$ & 4,635 & 1,130 & 4.10 \\
\hline E035 & 3,475 & 830 & 4.19 \\
\hline Total & $\mathbf{1 9 , 4 2 4}$ & $\mathbf{4 , 4 4 0}$ & $\begin{array}{r}\mathbf{4 . 3 7} \\
\text { (average) }\end{array}$ \\
\hline
\end{tabular}

During the early winter months of 2005, there was an insufficient number of chargers in the IndyGo garage. As a result, some buses had to be self-charged overnight to be ready for pullout the next morning. IndyGo performed the self-charging by running the MicroTurbine to bring the battery pack SOC to $100 \%$. Self-charging the batteries overnight with diesel fuel, rather than charging the batteries with electricity, reduced the fuel economy of the buses. Although the buses could begin the route at less than $100 \%$ SOC, refueling would have been required to complete the route. It was not possible to measure the exact reduction in fuel economy for this study. Ebus replaced the chargers in March 2005 with better, more compatible chargers.

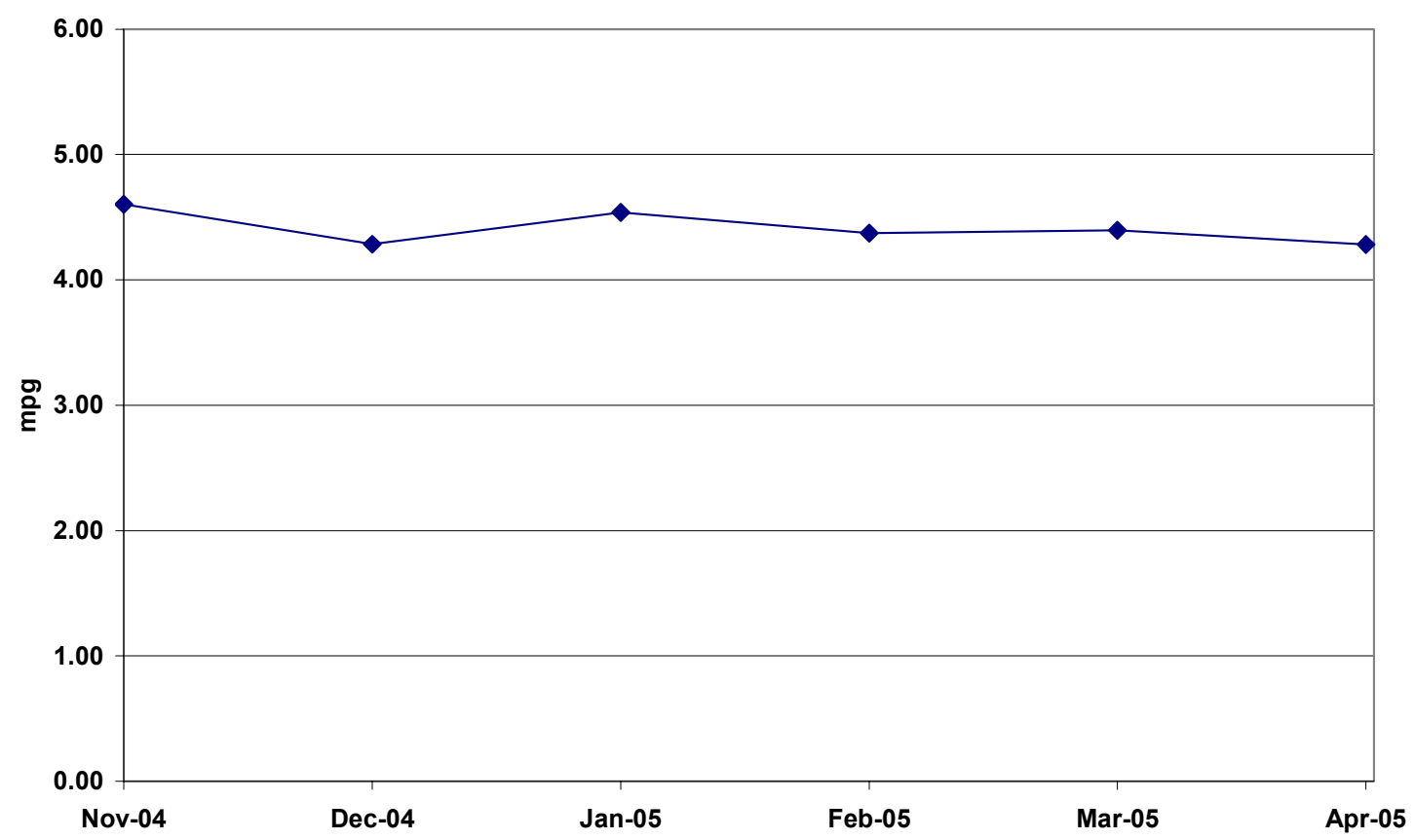

Figure 10. IndyGo Fuel economy during the 6-month evaluation period 


\section{Fuel Costs}

The average price of the diesel fuel that IndyGo purchased during the 6-month evaluation period was $\$ 1.53$ per gallon. This cost-per-gallon average is for fuel purchased between November 2004 and April 2005.

\section{Maintenance}

The maintenance costs evaluation reflects the data collection period (November 2004 through April 2005). This evaluation also includes an expanded overview of cumulative costs per mile beginning in June 2004, when maintenance work orders were first collected from IndyGo. A standard rate of $\$ 50$ per hour was applied to all labor hours.

Table 7 is a breakdown of overall maintenance costs for each of IndyGo's five buses. The cost for bus E032 is significantly higher because a DC/DC converter for the air-conditioning system had to be replaced. IndyGo mechanics did not charge labor hours to replace the component because Ebus completed this work. However, IndyGo paid for the DC/DC converter.

Table 7. IndyGo Total Maintenance Cost Comparison

\begin{tabular}{|c|r|r|r|r|}
\multicolumn{7}{c|}{ (November 2004 through April 2005) } \\
\hline Bus & $\begin{array}{c}\text { Total } \\
\text { Mileage }\end{array}$ & $\begin{array}{c}\text { Labor } \\
\text { Hours }\end{array}$ & $\begin{array}{c}\text { Parts } \\
\text { Cost }\end{array}$ & $\begin{array}{c}\text { Cost/ } \\
\text { Mile }^{*}\end{array}$ \\
\hline E031 & 4,332 & 40 & $\$ 73$ & $\$ 0.48$ \\
\hline E032 & 2,336 & 42 & $\$ 1,790$ & $\$ 1.67$ \\
\hline E033 & 5,286 & 60 & $\$ 353$ & $\$ 0.63$ \\
\hline E034 & 4,658 & 37 & $\$ 646$ & $\$ 0.54$ \\
\hline E035 & 3,475 & 23 & $\$ 394$ & $\$ 0.44$ \\
\hline Total & $\mathbf{2 0 , 0 8 7}$ & $\mathbf{2 0 2}$ & $\mathbf{\$ 3 , 2 5 6}$ & $\begin{array}{c}\mathbf{\$ 0 . 6 6} \\
\text { (average) }\end{array}$ \\
\hline
\end{tabular}

${ }^{*}$ At an assumed labor cost of $\$ 50 / \mathrm{hr}$

Hybrid propulsion components in this study include the batteries, on-board charging, the battery chiller, the electric propulsion motor, and controls for the electric propulsion motor. Figure 11 shows the cumulative maintenance cost per mile for all vehicle systems and the cumulative maintenance cost of the hybrid system. There was a steep drop in both sets of costs in spring 2004, followed by a continuing but slow decrease.

The high cost noted in June 2004 was for the DC/DC converter replacement. The graph does not focus on this point ( $\$ 1.58$ per mile) because it was an initial startup cost. Between November 2004 and March 2005, the cumulative cost per mile decreases by approximately $2 \%$ for both the overall vehicle and the hybrid system. This trend is typical when a new technology is introduced into a fleet. The learning curves for drivers and maintenance technicians begin to stabilize with time and experience. 


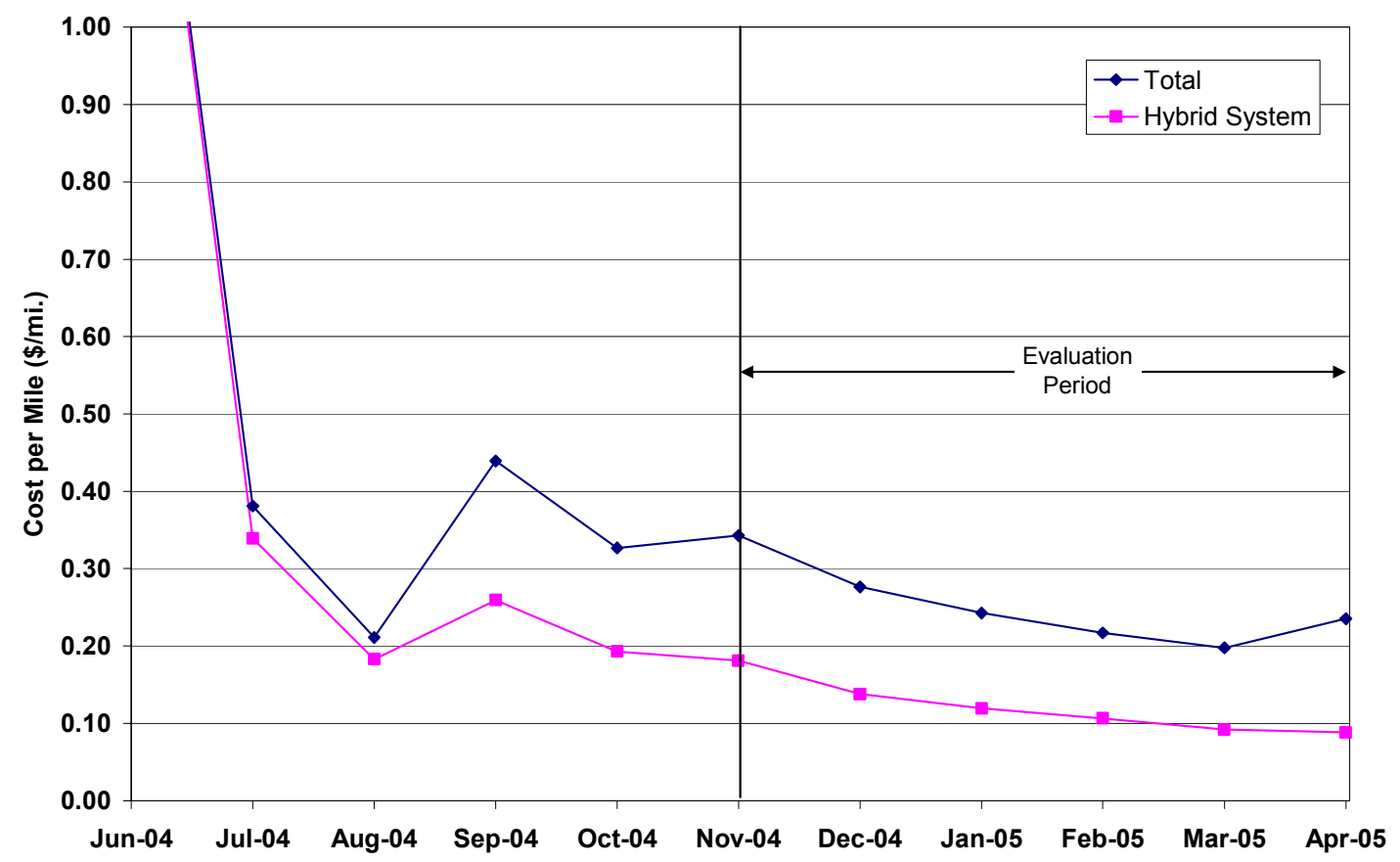

Figure 11. IndyGo Cumulative maintenance costs per mile

Figure 12 shows the cost of parts and labor for each vehicle system between November 2004 and April 2005. Repairs to the propulsion system accounted for $75 \%$ of these costs. Preventive maintenance inspections and parts contributed $11 \%$ to overall vehicle maintenance costs. These included general inspection time, filter care services for the turbine, and fuel filter replacements. The braking system, which incorporates regenerative braking, contributed only $7 \%$ to the overall costs. "Other" maintenance, which included minor repairs to the chassis and power steering, accounted for $2 \%$ of the costs. Detailed descriptions of the maintenance performed on the propulsion system follow.

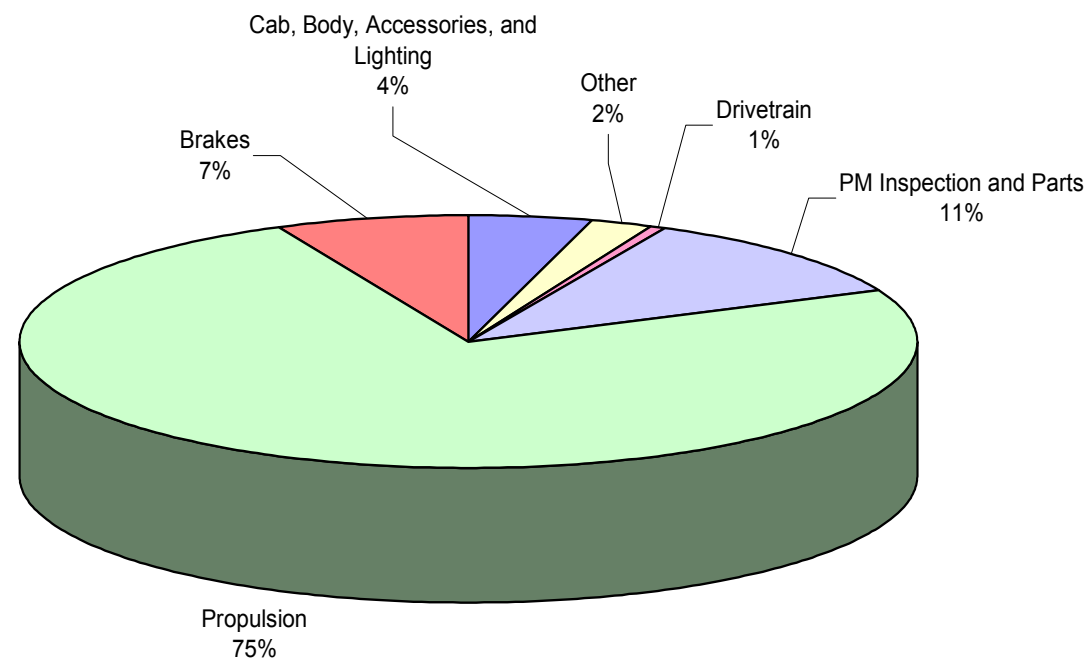

Figure 12. Maintenance cost by vehicle system (Labor + Parts) 


\section{Specific Component Issues and Resolutions}

Before and during the evaluation period, IndyGo experienced maintenance issues with specific components or vehicle subsystems and performed repairs on them. Many of these components are unique to the Ebus hybrid system. They include the following:

- Traction batteries

- Battery chiller

- Electric propulsion motor

- Controls for the electric propulsion motor

- MicroTurbine

- Climate control.

Although the electric propulsion motor is included, no repairs were performed on it during the 6month period and no major repairs were performed during the expanded evaluation period. A total cost breakdown for the propulsion system is shown in Table 8 and in Figure 13.

Table 8. IndyGo Propulsion System Costs (November 2004 to April 2005)

\begin{tabular}{|c|r|r|r|r|}
\hline Bus & $\begin{array}{c}\text { Total } \\
\text { Mileage }\end{array}$ & $\begin{array}{c}\text { Labor } \\
\text { Hours }\end{array}$ & $\begin{array}{c}\text { Parts } \\
\text { Cost }\end{array}$ & $\begin{array}{l}\text { Cost/ } \\
\text { Mile }^{*}\end{array}$ \\
\hline E031 & 4,332 & 27 & $\$ 2$ & $\$ 0.31$ \\
\hline E032 & 2,336 & 34 & $\$ 1,797$ & $\$ 1.50$ \\
\hline E033 & 5,286 & 30 & $\$ 134$ & $\$ 0.31$ \\
\hline E034 & 4,658 & 30 & $\$ 553$ & $\$ 0.44$ \\
\hline E035 & 3,475 & 8 & $\$ 309$ & $\$ 0.20$ \\
\hline \multicolumn{7}{|c|}{ Total } & $\mathbf{2 0 , 0 8 7}$ & $\mathbf{1 2 9}$ & $\mathbf{\$ 2 , 7 9 5}$ & $\begin{array}{c}\$ 0.46 \\
\text { (average) }\end{array}$ \\
\hline
\end{tabular}

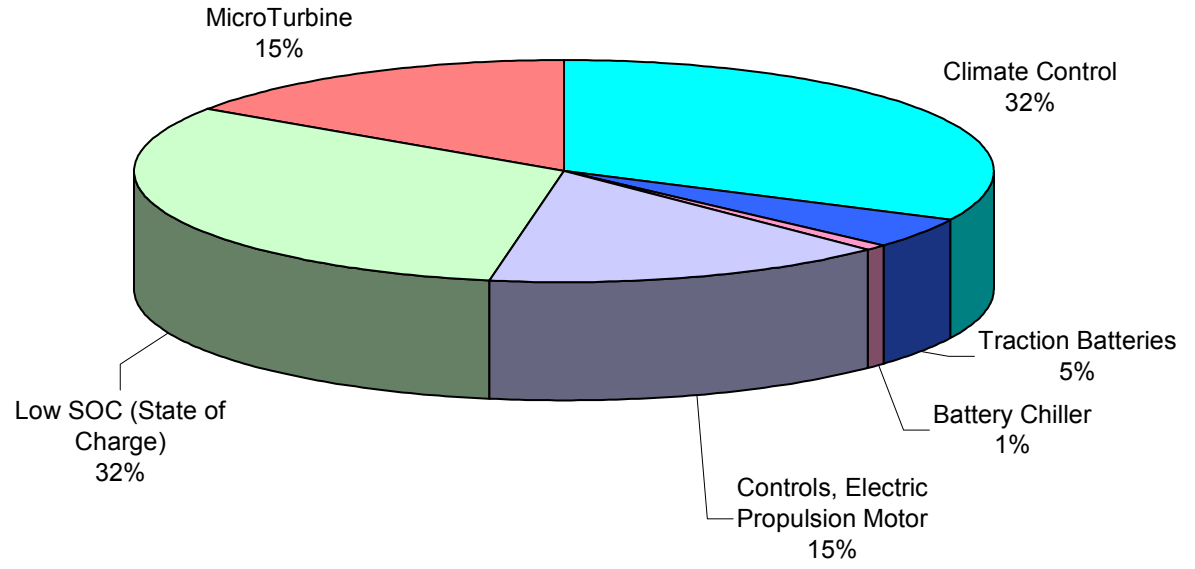

Figure 13. Propulsion system maintenance costs (Labor + Parts) 


\section{Climate Control}

The climate control components that draw power from the batteries and associated labor make up $32 \%$ of the maintenance costs for the propulsion system. The DC/DC converter for the airconditioning system (noncharging) is the major contributor to this cost, at $\$ 1,790.25$; one had to be replaced on bus E032 during the 6-month period. An additional noncharging DC/DC converter was replaced in September 2004 (outside the detailed evaluation period). All of the DC/DC converters were replaced in fall 2003.

\section{Electric Propulsion Motor Controls}

Controls for the electric propulsion motor contributed $15 \%$ of the total propulsion system maintenance cost. Major contributors to this cost were the labor hours spent on the traction controls and inverters. Although replacement traction inverters were covered under the Ebus warranty, the mechanics at IndyGo performed the labor.

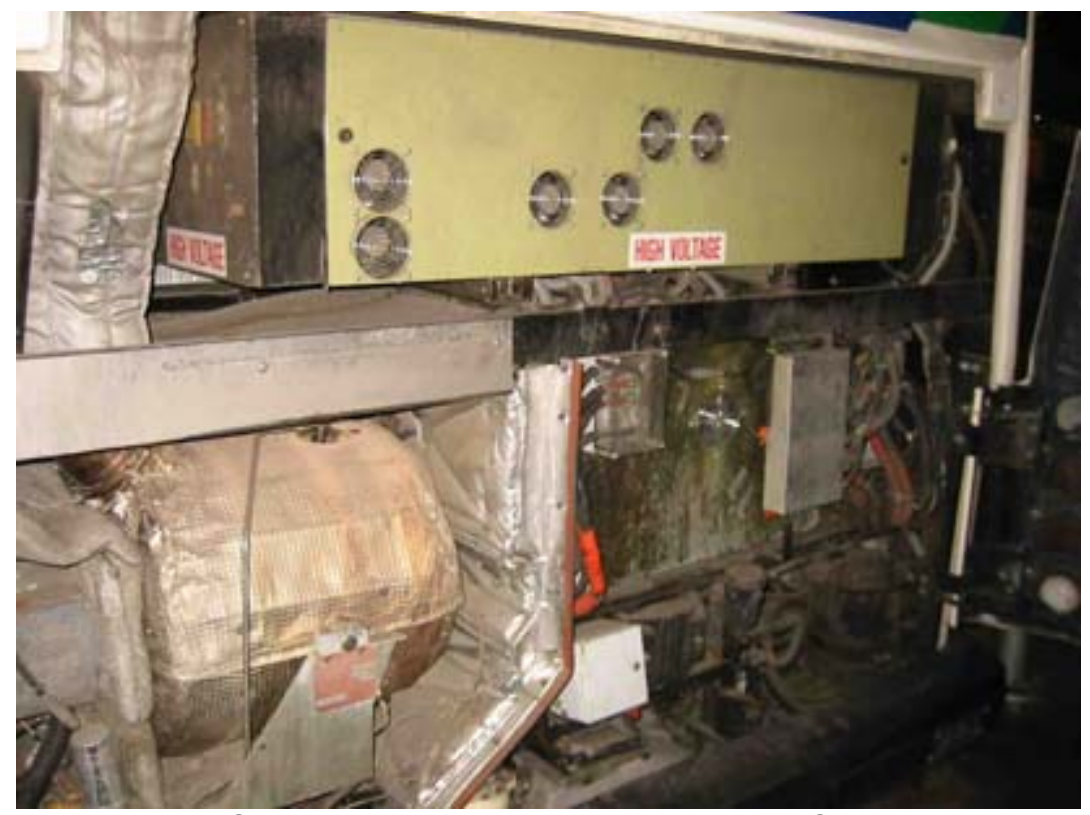

Figure 14. Capstone MicroTurbine Assembly (Source: NREL)

\section{Capstone MicroTurbine}

An additional $15 \%$ of the total propulsion costs were for maintaining the MicroTurbine. A leading contributor was the cost of replacing parts that activate the MicroTurbine. Replacing one exciter and two igniters contributed \$241 and \$305, respectively, to the total cost. When an igniter fails, the MicroTurbine cannot activate to elevate the battery SOC as programmed. A "turbine fault" message appears on the onboard display next to the operator. If the operator is not aware of this message, the battery SOC will be depleted until the bus is unable to operate and the result is a road call. Capstone is currently developing an improved igniter design.

\section{Traction Batteries}

Only 5\% of total propulsion costs were for maintaining traction batteries and on-board charging components. One Ebus NiCd battery was replaced at a cost of \$133.99 during this period. However, IndyGo had to purchase some higher cost replacement parts outside the detailed 
evaluation period. A DC/DC converter that charges the $13.5 \mathrm{~V}$ battery cost $\$ 1,375.20$ to replace. One was replaced in June 2004, the other in September 2004.

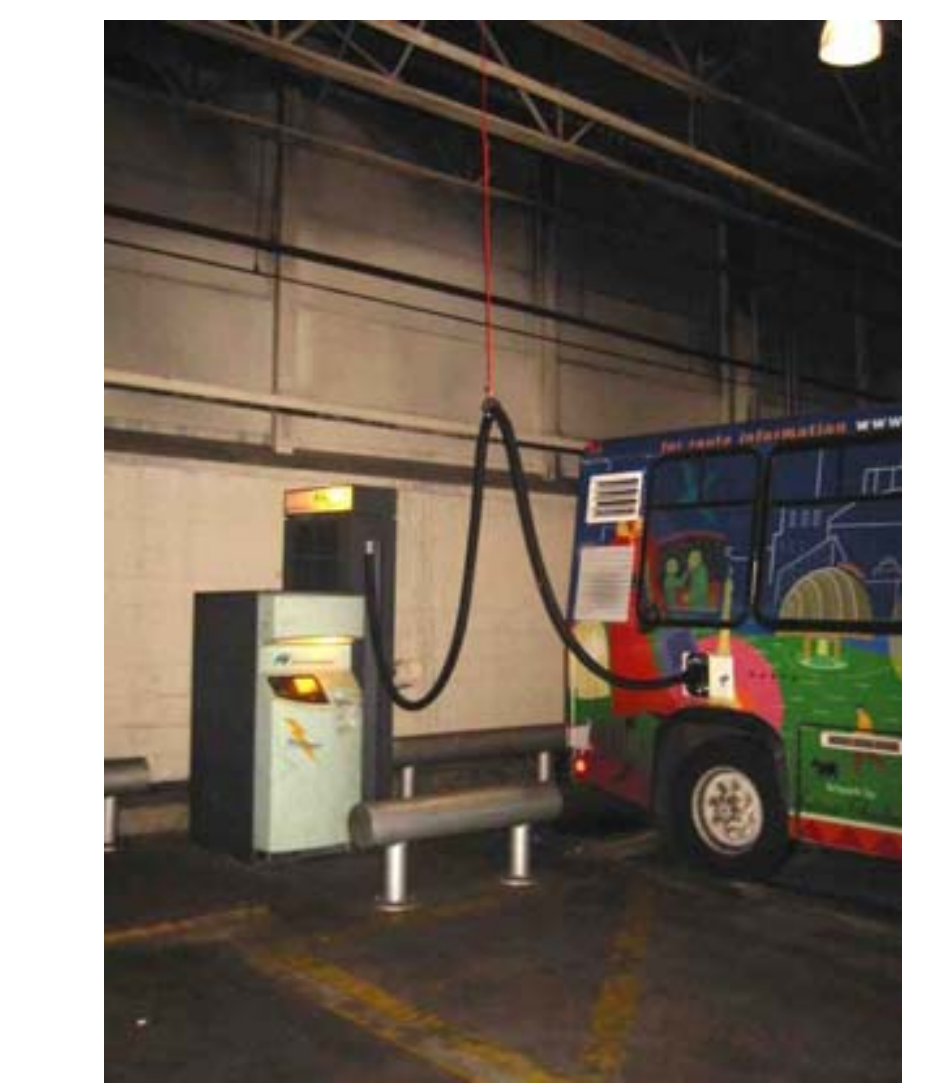

Figure 15. IndyGo Ebus at Charging Station (Source: NREL)

\section{Low SOC}

Before beginning the route each morning, mechanics started the hybrid electric buses 30 minutes early to allow the MicroTurbine to ignite and warm up. Early start-ups ensured that the diesel fuel would ignite the MicroTurbine properly. However, drivers unfamiliar with the buses and the early start-ups would often "start" the vehicles without knowing they were already on. When this happens, the MicroTurbine shuts down, but the bus continues to run. Beginning the route with the MicroTurbine off caused the bus to lose the ability to recharge its batteries and to shut down. When that happened, the buses had to be towed back to the maintenance garage to be recharged.

Significant costs - $32 \%$ of all propulsion costs - were incurred from "low SOC" reports resulting from having to tow the buses after batteries ran low on charge and shut down. In some cases, low SOC reports were the result when a driver accidentally shut down the MicroTurbine before beginning a route. Because the MicroTurbine operates quietly, some drivers might not have been aware that it was running when they rekeyed the ignition. The resulting shutdown prevented the batteries from reaching the required SOC.

As noted earlier, the Capstone igniter was occasionally unable to ignite diesel fuel and activate the MicroTurbine. If the MicroTurbine was not activated properly when the battery SOC fell below $60 \%$, the vehicle would continue to operate until the low SOC rendered it inoperable. 
Low-SOC-related costs are in a separate category. They are potentially resolvable, and Ebus attempted to fix the associated problems by means of a computer upgrade. This is discussed further in the section on road calls.

\section{Campaigns}

As the new hybrid electric technology was implemented in the IndyGo fleet, some campaigns and system changes were needed to improve the comfort, safety, and maintainability of the buses. The DC/DC converter upgrades to the air-conditioning system were followed by two additional upgrades to the air-conditioning system's communication module. In addition, a highvoltage cable and fuse exposed through the battery box was enclosed in these buses following the ignition incident discussed earlier.

Another problem involved correcting the tone ring on one vehicle's braking system in fall 2004. During braking, the vehicle's speed sensor detected an incorrect number of teeth on the tone ring, which prevented the sensor from generating the correct voltage. Although the occurrences were limited, the inconsistency caused the vehicle to lose braking power randomly. Only one bus had this problem, but all the buses were checked as part of this campaign.

In spring 2005, Ebus changed some software on the buses in order to make the MicroTurbine run all the time at a reduced level and thus constantly charge the battery pack. This upgrade-a significant change from the original design of the technology — was made to prevent future low SOC road calls. Since the turbines run on diesel fuel, running them all the time will reduce the fleet's fuel economy somewhat.

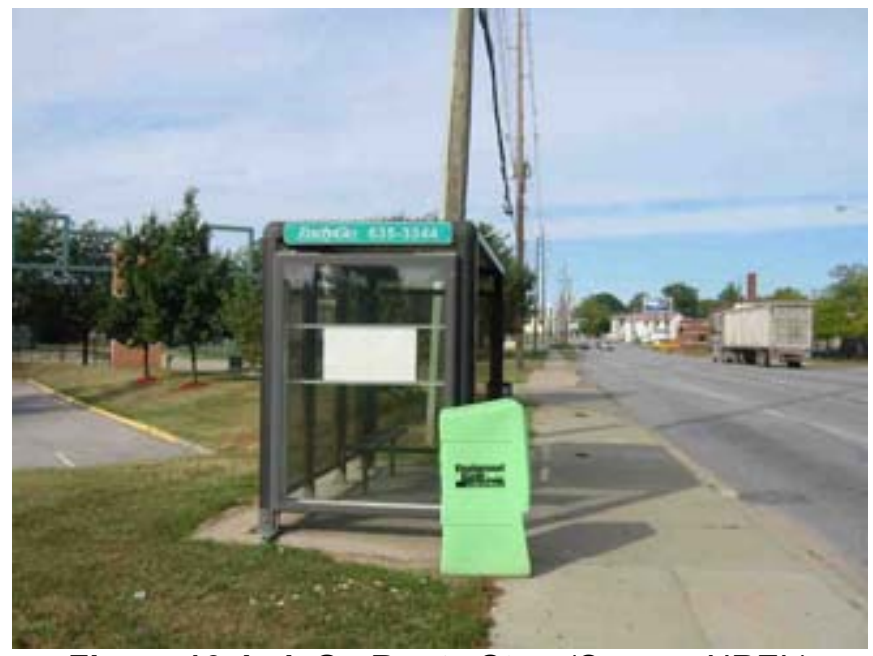

Figure 16. IndyGo Route Stop (Source: NREL)

\section{Road Calls}

IndyGo defines a road call as a failure that needs immediate attention while the bus is in service. All the road calls reported during the evaluation period were related to the battery pack's low SOC (see Table 9). In many cases, this could be attributed to the shutdown of the MicroTurbine, as noted earlier. In other cases, diesel fuel failed to reignite and fuel the MicroTurbine while on the route. 
To alleviate this road call pattern, Ebus carried out a software upgrade campaign. The software upgrade, which keeps the MicroTurbine running constantly at a reduced level unless the driver decides otherwise, ensures that the MicroTurbine will not have to reignite while on the road. After the MicroTurbine is ignited and running, this software change makes it unlikely to shut down.

The number of low SOC occurrences per mile of revenue service trailed off over time, and this helped to increase the number of cumulative miles between road calls. This trend is shown in Figure 18, which shows the number of cumulative miles between road calls (MBRC) over an expanded evaluation period and captures some early experiences with the technology at IndyGo.

Table 9. IndyGo Road Call Comparison

\begin{tabular}{|c|c|c|}
\hline Bus & $\begin{array}{l}\text { Total Road } \\
\text { Calls }\end{array}$ & $\begin{array}{l}\text { Low-SOC } \\
\text { Road Calls }\end{array}$ \\
\hline E031 & 5 & 5 \\
\hline E032 & 2 & 2 \\
\hline E033 & 2 & 2 \\
\hline E034 & 7 & 7 \\
\hline E035 & 0 & 0 \\
\hline Total & 16 & 16 \\
\hline
\end{tabular}

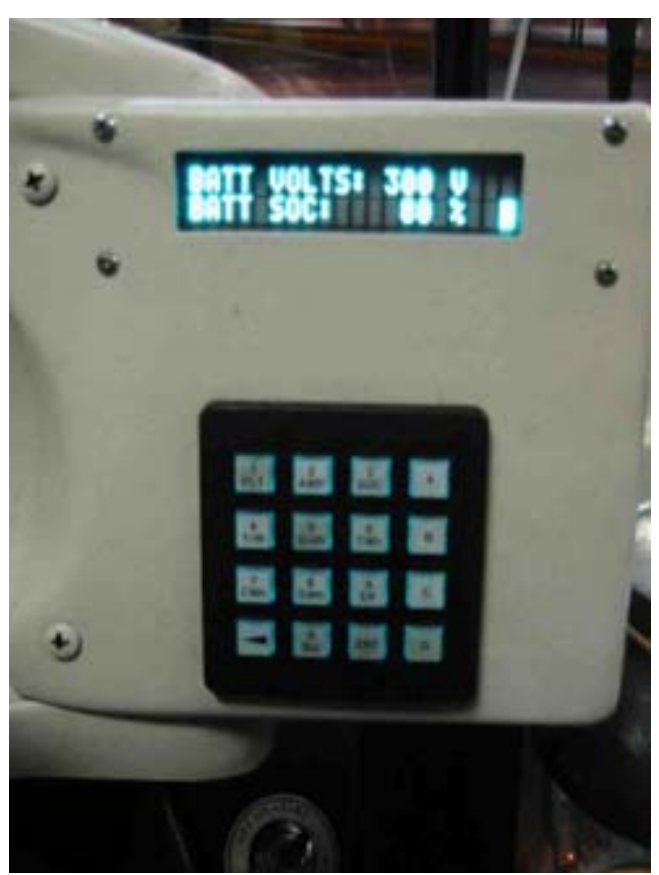

Figure 17. Battery Charger Display (Source: NREL) 


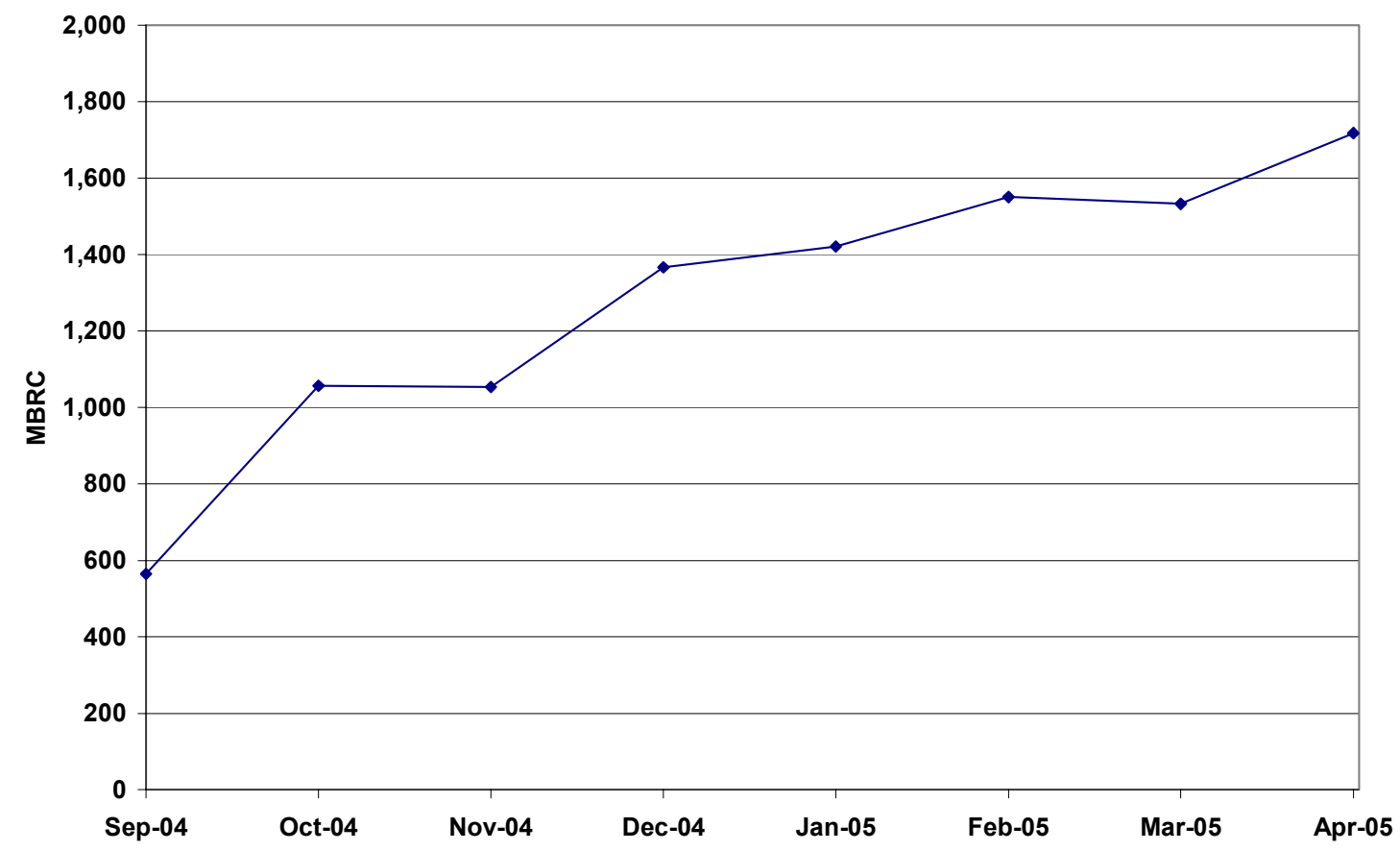

Figure 18. IndyGo Cumulative miles between road calls

\section{Total Operating Costs}

The overall operating costs of the Ebus fleet during the 6-month evaluation period are shown in Table 10. The overall costs incorporate maintenance and fuel costs for the vehicles. No consistent data are available on the cost of recharging the batteries overnight; therefore, they are not included in this analysis.

The average cost of diesel fuel between November 2004 and April 2005 was \$1.53 per gallon. As described in the section on maintenance, bus E032 had higher costs for parts after the replacement of a DC/DC converter in the air-conditioning system. The rest of the fleet (excluding bus E032) had an average parts cost of $\$ 0.88$ per mile.

Table 10. IndyGo Overall Operating Costs

\begin{tabular}{|c|r|r|r|r|r|}
\hline Bus & Miles Driven & \multicolumn{1}{|c|}{$\begin{array}{l}\text { Labor } \\
\text { Hours }\end{array}$} & \multicolumn{1}{c|}{$\begin{array}{c}\text { Parts } \\
\text { Cost }\end{array}$} & \multicolumn{1}{c|}{$\begin{array}{l}\text { Fuel } \\
\text { Cost }\end{array}$} & Cost/Mile \\
\hline E031 & 4,145 & 40 & $\$ 73$ & $\$ 1,359$ & $\$ 0.83$ \\
\hline E032 & 1,883 & 42 & $\$ 1,790$ & $\$ 783$ & $\$ 2.48$ \\
\hline E033 & 5,286 & 60 & $\$ 353$ & $\$ 1,652$ & $\$ 0.95$ \\
\hline E034 & 4,635 & 37 & $\$ 646$ & $\$ 1,729$ & $\$ 0.91$ \\
\hline E035 & 3,475 & 23 & $\$ 394$ & $\$ 1,270$ & $\$ 0.81$ \\
\hline Total & $\mathbf{1 9 , 4 2 4}$ & $\mathbf{2 0 2}$ & $\mathbf{\$ 3 , 2 5 6}$ & $\mathbf{\$ 6 , 7 9 3}$ & $\begin{array}{r}\mathbf{\$ 1 . 0 4} \\
\text { (average) }\end{array}$ \\
\hline
\end{tabular}

\section{Summary of Results at IndyGo}

IndyGo implemented the Ebus hybrid electric buses as a technical development effort. The most significant lesson learned in this experience was that the technology was still in developmental 
stages. This was the first time that diesel fuel was used with this turbine in a vehicle application. Comments based on availability, applicability, reliability, and training follow:

\section{Availability}

- It was a struggle to keep two of the five buses on the road at a time. The goal had been to keep three on the road 12 hours per day.

- The desired technician-to-bus ratio during the evaluation period was 1:5 or less, but often a 2:5 ratio was needed.

- Sometimes IndyGo had to let a bus sit in the garage for a month while replacement parts were on order.

- The buses were available for less than one-third of the miles they had been scheduled to run. IndyGo found the buses to be less reliable than conventional diesel buses.

\section{Applicability}

- Diesel fuel is initially somewhat harder to ignite than propane. This was the first vehicle to use the diesel-fuel turbine combination. Capstone is currently developing an improved igniter for the system.

- In spite of the reduced usage, trends indicated some successes in terms of the cost per mile and fuel economy of the buses.

\section{Reliability}

- The reliability of the buses was greatly reduced by road calls resulting from a low SOC in the battery bank. The battery SOC was depleted as a result of MicroTurbine shutdowns, which occurred for two reasons:

$\circ$ Bus operators restarted the buses with the MicroTurbine running, triggering a shutdown.

- Diesel fuel failed to ignite and cycle on the MicroTurbine to elevate the SOC during operation.

Although occurrences of low SOC diminished over time, it seems feasible that these road calls may have been eliminated following the software upgrade that causes the MicroTurbine to run all the time at a reduced level. This upgrade occurred after the evaluation period.

\section{Training}

- IndyGo guided the introduction and implementation of the new technology by training mechanics and drivers. Extensive follow-up training was necessary throughout this process.

- Retaining details about operating the new technology proved to be a challenge for many drivers. One instance of this involved drivers who had not driven these buses for a while and were not aware, because of the quietness of the MicroTurbines, that the buses had already been running in the garage. Attempts to restart these buses caused the shutdowns and road call situations noted earlier. 
IndyGo has continued to implement new technologies since the introduction of the Ebus hybrid electric buses. In 2004, two full-sized hybrid electric buses with a General Motors-Allison hybrid system were acquired and put into service. Although IndyGo received reasonable service from Ebus, there are no current plans to purchase more of these buses.

\section{Fleet Experience: KAT}

\section{Fleet Profile}

The Knoxville Area Transit, or KAT (www.ci.knoxville.tn.us/KAT), operates in metropolitan Knoxville, Tennessee. Bus service includes 64 buses, 22 vans, and 14 trolleys. KAT provides 25 bus and three trolley routes during peak service. In 2004, KAT provided service to 3.2 million passengers, the highest amount in 20 years. Figure 10 shows the KAT facility.

KAT was recently awarded the American Public Transportation Association (APTA) Public Transportation System Outstanding Achievement Award for 2004 (for transit systems providing service to 1 million to 4 million passengers). This award was based on KAT's increased ridership, Clean Fuels Program, and marketing programs.

Because of regional air quality conditions and concerns expressed by stakeholders, KAT formulated and implemented a Clean Fuels Program. After analyzing the costs and implementation issues associated with various available alternative fuel technologies, KAT selected LPG as the most viable option for its fleet. LPG offered several advantages, including these:

- A local supplier could maintain the fuel supply and the fueling infrastructure.

- Costs would be lower in comparison to the cost of using diesel.

- Noise levels would be lower than those associated with diesel.

- LPG vehicles provided a close fit with KAT's plan to use smaller, neighborhood-friendly vehicles as circulators that would feed the larger transit network.

BAF Industries provided technical training to KAT's maintenance staff and installed the LPG fueling system at KAT's facilities while KAT maintenance personnel observed the installation. This training familiarized the KAT mechanics with the systems and helped to streamline later diagnoses and repairs of system problems.

In addition to the four Ebus trolleys studied during the evaluation, the Clean Fuels Program at KAT includes five new LPG-fueled cutaway vans, several larger hybrid electric buses, and a grant to use B20, a biodiesel blend, in diesel vehicles. 


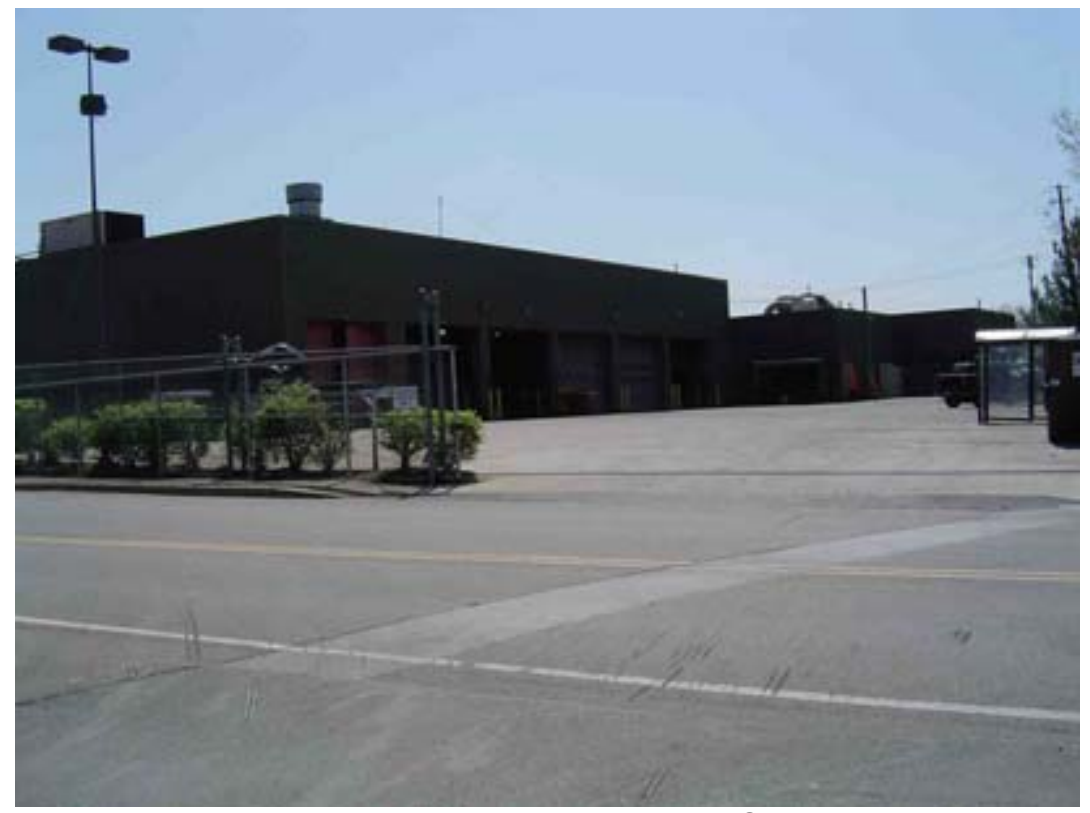

Figure 19. KAT Maintenance Facility (Source: NREL)

\section{Implementation Experience}

In 2002, KAT received a CMAQ grant for $\$ 900,000$. Local matching funds of $20 \%$ of that amount brought the total to $\$ 1.1$ million. These funds were originally intended for purchasing electric vehicles and support equipment; however, the Knoxville Regional Transportation Planning Organization expressed considerable interest in expanding the popular downtown trolley system. Therefore, the CMAQ funds were used to purchase an electric vehicle for the trolley system. KAT's objectives were to comply with the requirements of the CMAQ and the source of the matching funds and to apply a clean fuel technology to a high-traffic route.

The decision-making process was framed by a number of limitations, including the technologyspecific nature of the funding source, route characteristics, the fuel infrastructure and supply, and the time frame. Steep grades on the downtown route were deemed excessive for conventional battery-powered electrics, and an APU was considered necessary to manage the incline and range requirements. The hybrid trolley available through Ebus was designed specifically for diesel fuel, which was unacceptable given KAT's commitment to lower emissions.

KAT's experience with LPG and the existing infrastructure made this clean fuel an appealing choice. Only two manufacturers of turbine APUs were available. Ebus had recently begun developing a hybrid electric trolley using a Capstone MicroTurbine fueled by LPG. KAT was interested in being an early deployer of this technology, so the transit authority volunteered to provide significant feedback.

After the final vehicle design was tested, KAT purchased four hybrid electric trolleys that were received in December 2003. KAT continued to study route characteristics and requirements to ensure that the trolleys were an appropriate match. KAT found that the 22-foot trolleys were adept at navigating the narrow downtown streets and close quarters at turnaround points. They were also light enough to drive on the local viaduct. After more than four months of evaluation 
and planning, KAT deployed the Ebus trolleys on its new Red Line, which serves downtown Knoxville during peak commuter hours.

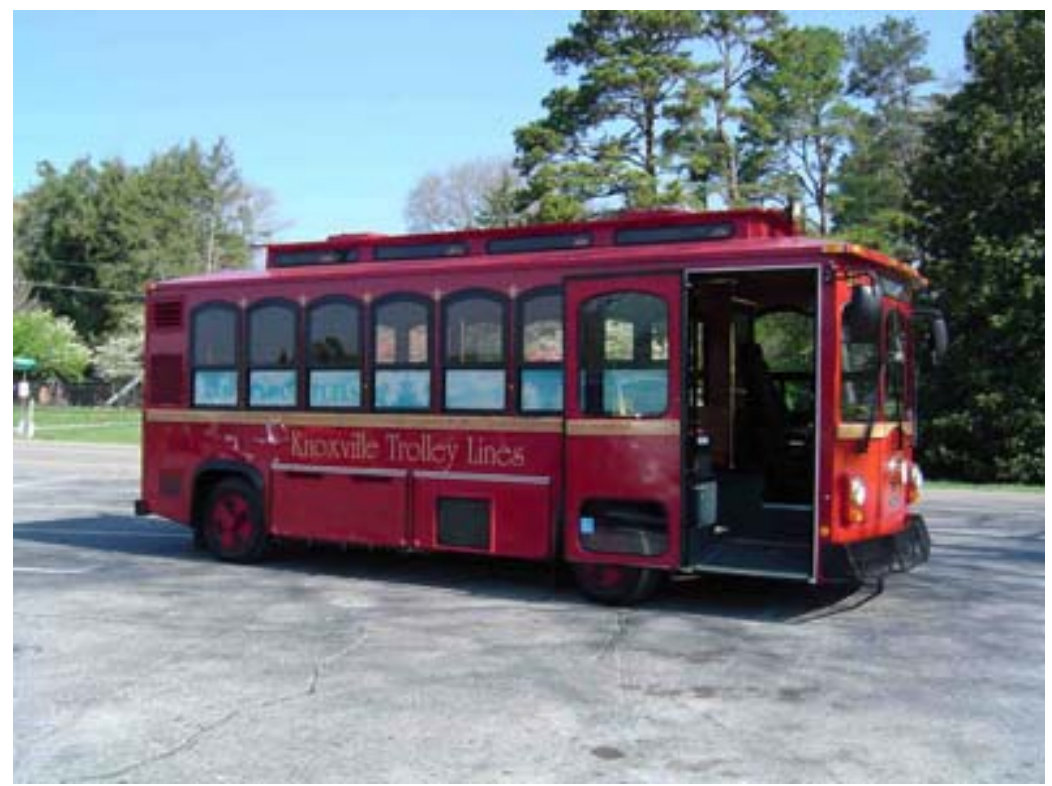

Figure 20. KAT Ebus Trolley (Source: NREL Photo)

KAT's LPG fueling infrastructure was expanded during summer 2005 to accommodate the Ebus trolleys. Figure 21 shows the original and upgraded fueling facility. Figure 22 shows the onboard 50-gal LPG storage tank used in the Ebus trolleys.
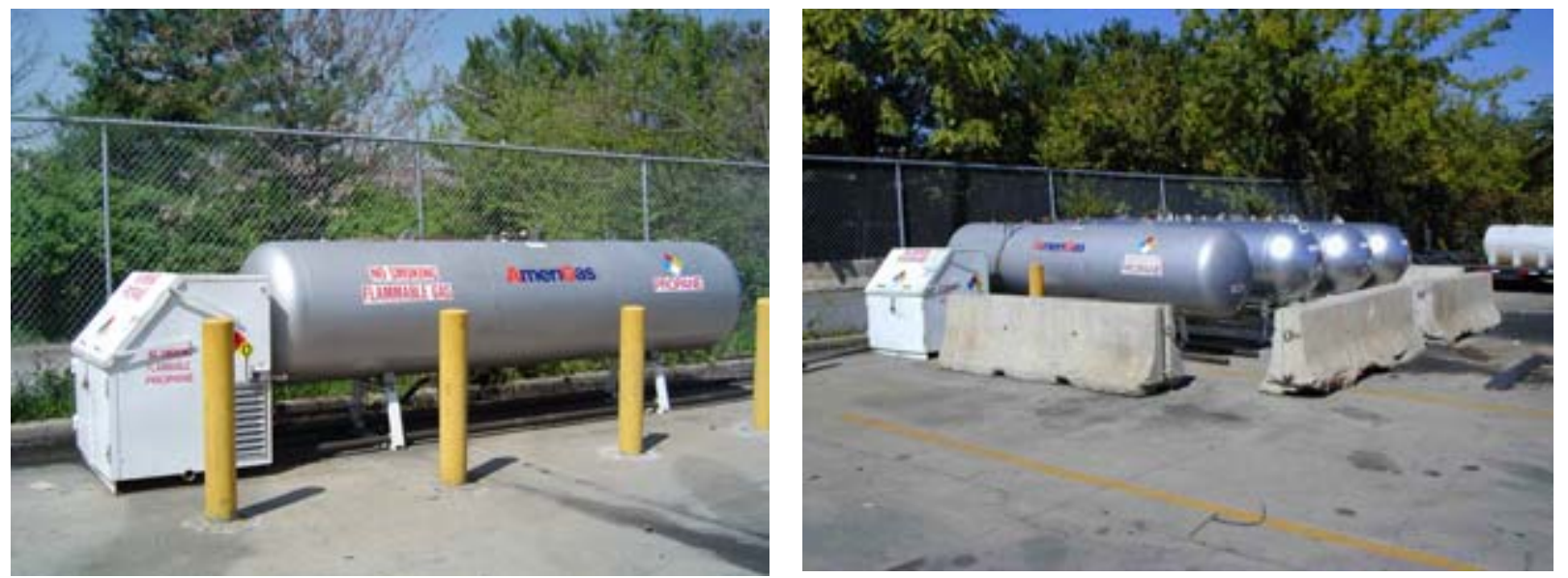

Figure 21. Original and upgraded LPG fueling station 


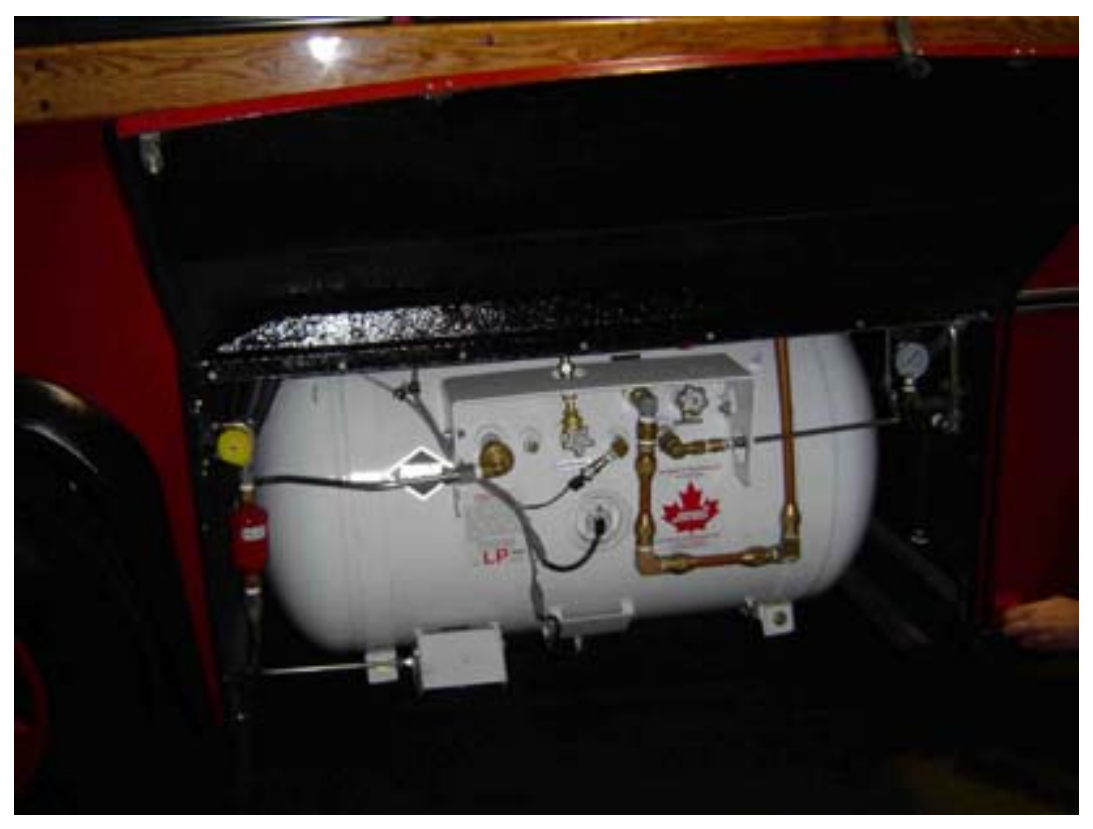

Figure 22. On-board LPG storage

Temporary chargers provided by Ebus were also installed in the KAT maintenance facility to provide opportunity charging overnight. In early 2005 , only one of these two chargers was operating because of an internal failure. Ebus replaced the two chargers with two upgraded models in spring 2005. Figure 23 shows the first version of charger.

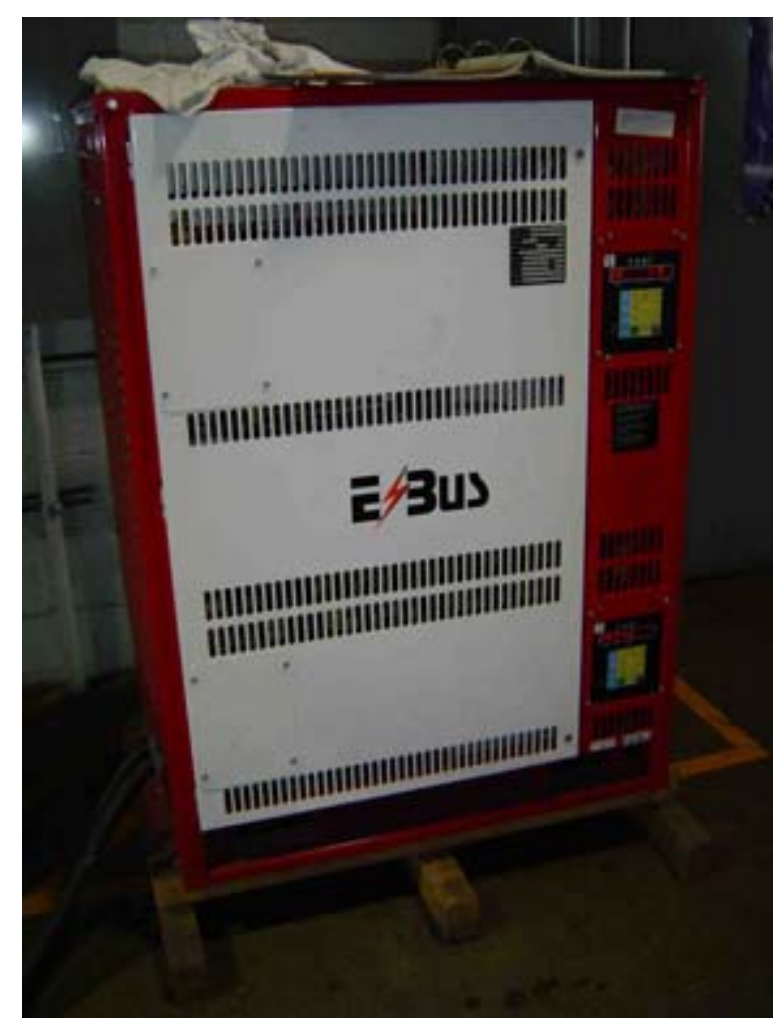

Figure 23. Original KAT charger 
No other modifications were made to KAT's maintenance facility for the LPG Ebus trolleys. LPG is heavier than air and therefore does not require the kind of roof ventilation employed by fleets using CNG or hydrogen. KAT's maintenance facility uses lifts rather than pits, which is conducive to handling LPG safely.

\section{KAT Vehicle Use and Performance}

Figure 24 shows the mileage accumulated by the trolleys over a 12-month data-collection period. In August 2004, a limited number of miles were accrued because the trolleys were deactivated for safety reasons following a fire at IndyGo. After the trolleys were placed back in service in September 2004, they steadily accrued miles through the evaluation period of December 2004 to May 2005. The four trolleys accumulated almost 18,000 miles during the 12 months of data collection and nearly 11,000 miles during the 6-month evaluation period.

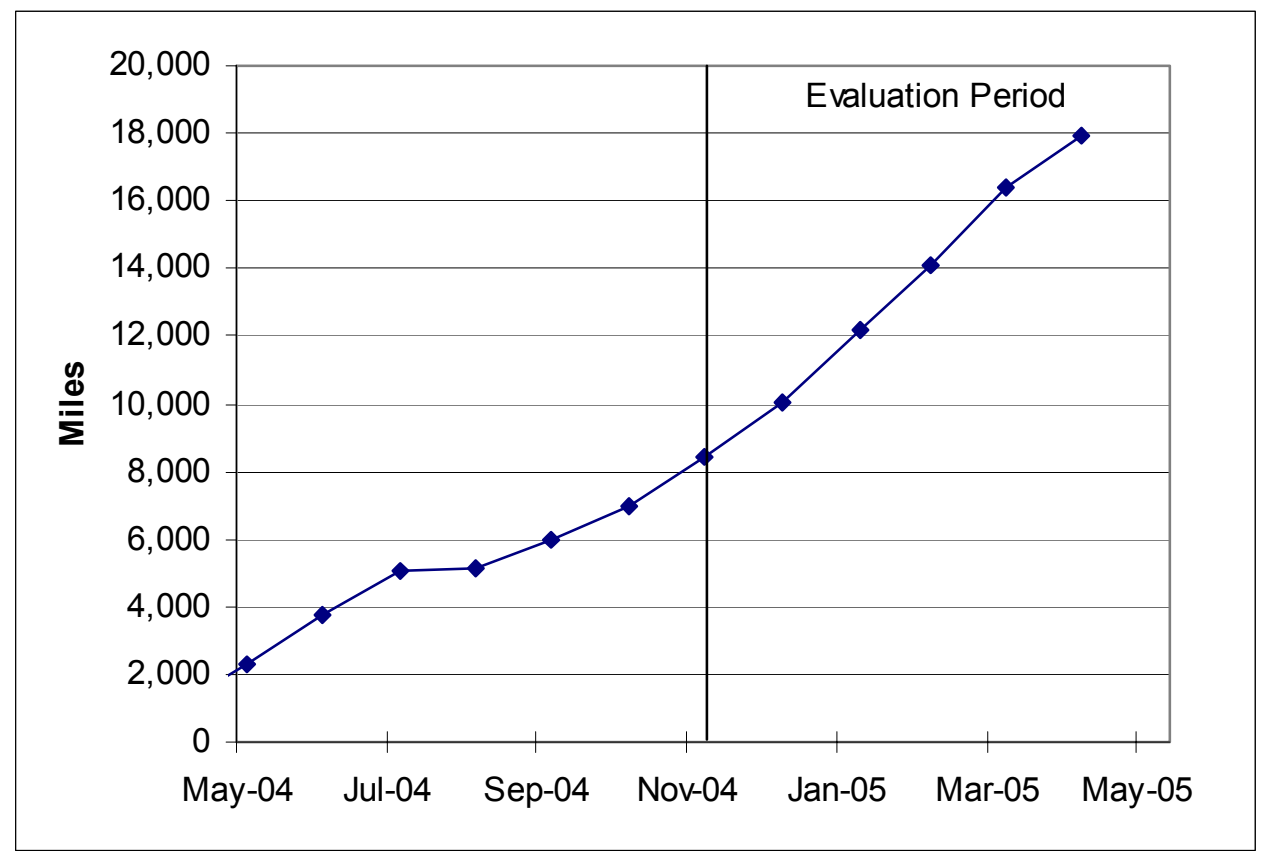

Figure 24. KAT Total mileage accumulation for the four Ebus trolleys

\section{Duty Cycle}

The Red Line provides commuter service from new parking facilities to downtown. This new route was added to reduce congestion in downtown Knoxville. The route starts at the Knoxville Civic Coliseum on the edge of downtown and continues through the northern downtown area, including Market Square, the Tennessee Valley Authority, and Gay Street. The Red Line circulates every 7 minutes during peak commuting hours on weekday mornings and afternoons. Two trolleys are on the route in the morning, and two in the afternoon. Each trolley is driven 3 hours in the morning and 2.5 hours in the afternoon, for a total of 11 daily route hours. The Red Line is shown in Figure 25 as part of the overall system map in Knoxville. Additional route and duty cycle characteristics are presented in Table 11. 


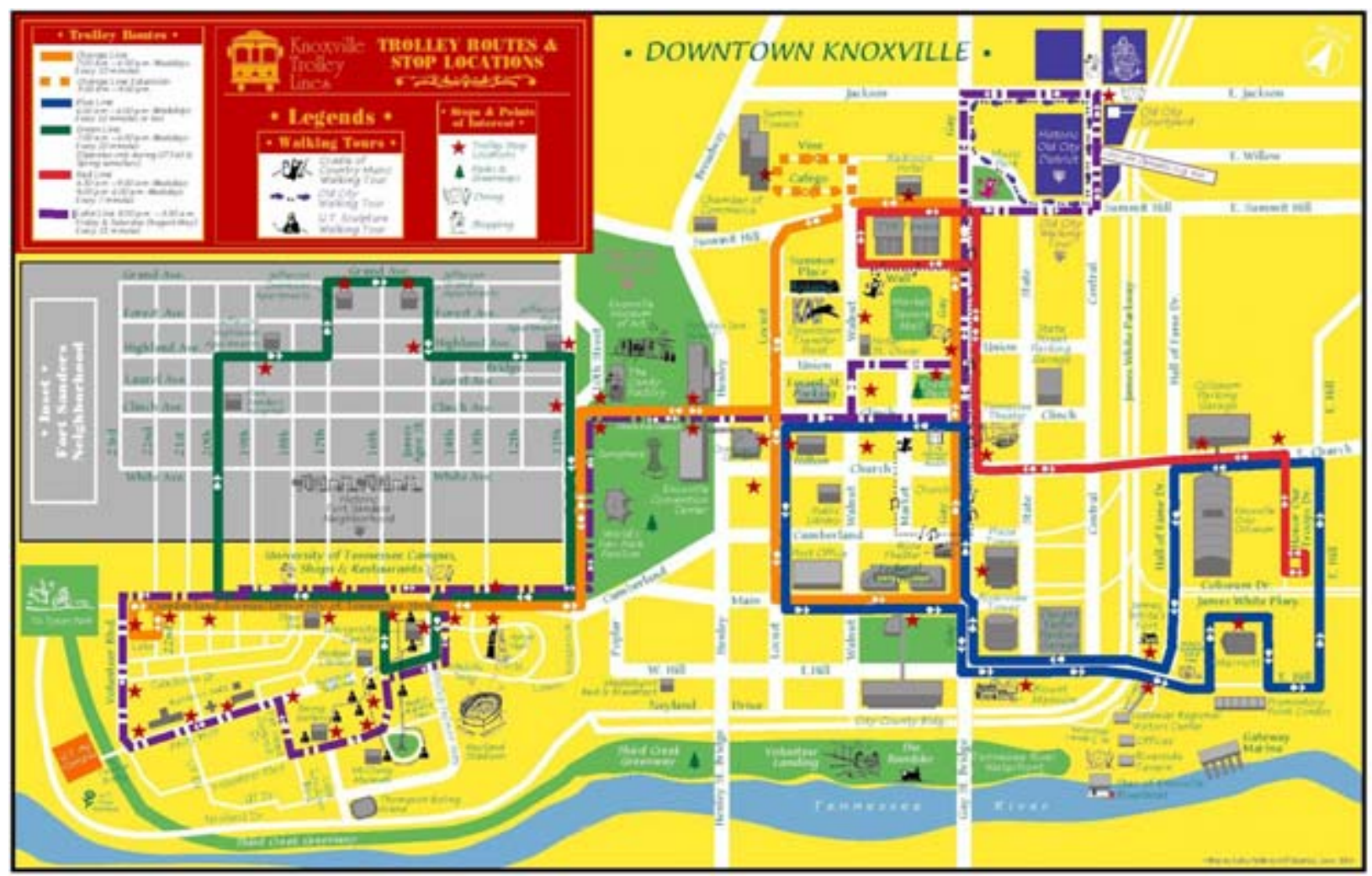

Figure 25. Red Line and other trolley routes in Knoxville

Table 11. KAT Red Line Duty Cycle Characteristics

\begin{tabular}{|l|l|}
\hline Terrain & Hilly, light city driving \\
\hline Climate & \\
Temperature (High/Low) & $87^{\circ} / 26^{\circ} \mathrm{F}$ \\
Annual Rainfall & $47.1 \mathrm{in}$. \\
Annual Snowfall & 11.5 in. \\
\hline Route Length & 2.6 miles \\
\hline Revenue Mileage/Day & 82.8 \\
\hline Total Mileage/Day & 94 \\
\hline Loops/Day & 36 \\
\hline Overall Average Speed & $8.5 \mathrm{mph}$ \\
\hline Average Passenger Load & At or near capacity (29) \\
\hline Stops per Loop & Four to six, depending on passenger \\
& needs \\
\hline Significant Grades & Two \\
\hline
\end{tabular}

\section{Fuel Economy Results}

As noted earlier, fuel economy calculations are based solely upon miles driven and liquid fuel volumes recorded. The effects of opportunity charging and self-charging of the traction battery packs were not quantified and are not considered. For the evaluation period, the four trolleys averaged 3.22 miles per diesel gallon equivalent (DGE). Fuel records are based on the volume of LPG dispensed. A fuel economy value based on miles per gallon of LPG is shown in Table 12. 


\section{Calculating Energy Equivalent Fuel Economy for LPG and Diesel}

KAT measures LPG use by volume when fuel is dispensed into the trolleys. To calculate the fuel economy, the gallons of LPG dispensed were converted into diesel gallon equivalents, or DGEs. A DGE represents the quantity of LPG that has the same energy content as one gallon of diesel fuel. This provides a real-world understanding of the trolley's fuel consumption. A conversion factor can be determined by comparing each fuel's energy content:

Diesel: 129,800 Btu

LPG: $84,300 \mathrm{Btu}$

$129,800 / 84,300=1.54 \mathrm{DGE}$

This means that $1 \mathrm{gal}$ of diesel has the same amount of energy as $1.54 \mathrm{gal}$ of LPG (these energy contents are based on density at 1 atmosphere at $60^{\circ} \mathrm{F}$ ). The fuel economy of each trolley can now be calculated by dividing the number of miles traveled by the LPG DGEs consumed by the trolley.

Table 12. KAT Fuel Economy Results for 6-Month Evaluation Period

\begin{tabular}{|c|r|r|r|r|r|}
\hline Trolley & $\begin{array}{l}\text { Mileage } \\
\text { Used }\end{array}$ & $\begin{array}{l}\text { Volume LPG } \\
\text { Used (gallons) }\end{array}$ & $\begin{array}{l}\text { Fuel Economy } \\
\text { (mpg LPG) }\end{array}$ & $\begin{array}{l}\text { Equivalent } \\
\text { Volume Diesel } \\
\text { Used (gallons) }\end{array}$ & $\begin{array}{l}\text { Fuel } \\
\text { Economy } \\
\text { (mpg diesel) }\end{array}$ \\
\hline 411 & 1,651 & 851 & 1.94 & 553 & 2.99 \\
\hline 412 & 3,391 & 1,719 & 1.97 & 1,116 & 3.04 \\
\hline 413 & 3,580 & 1,522 & 2.35 & 988 & 3.62 \\
\hline 414 & 2,149 & 1,055 & 2.04 & 685 & 3.14 \\
\hline & & $\mathbf{2 . 0 9}$ & $\mathbf{3 . 2 2}$ & $\begin{array}{r}\mathbf{3 4 2} \\
\text { (average) }\end{array}$ \\
\hline
\end{tabular}

Figure 26 presents average fuel economy values over 12 months. The high value for August 2004 is based on low mileage during that month. Note the slightly increasing trend in fuel economy values over the evaluation period, December 2004 to May 2005. Two issues likely contributed to this trend: (1) the decrease in "warm-up" (idle) time as the weather warmed in spring (see the section on maintenance for further information) and (2) self-charging of the trolley battery packs during the winter while waiting for replacement chargers to arrive. In the absence of the chargers, KAT ran the MicroTurbine to bring the battery packs' SOC to $100 \%$.

Although the trolleys could operate at less than 100\% SOC, more LPG would then be required to complete the route. Based on the mileage demand of the route, the LPG fuel economy, and the onboard fuel capacity, self-charging was deemed effective insurance against running out of fuel on the route or being forced to refuel mid-route. This practice stopped in March 2005, however, when standard off-board charging became available. Both warm-up and self-charging issues add to fuel use but not to accumulated mileage and therefore reduce fuel economy.

Additional factors contributing to fuel economy include these:

- Climate control auxiliary loads: Because of the high temperatures and humidity in summer and relatively cold temperatures in winter, the climate control requirements for 
the trolleys were significant. This issue is further addressed in the section on maintenance.

- High passenger load: Because they ran during peak commute hours, the trolleys operated with high passenger loads constantly.

- Significant grades: The two significant grades on the route helped to increase fuel consumption.

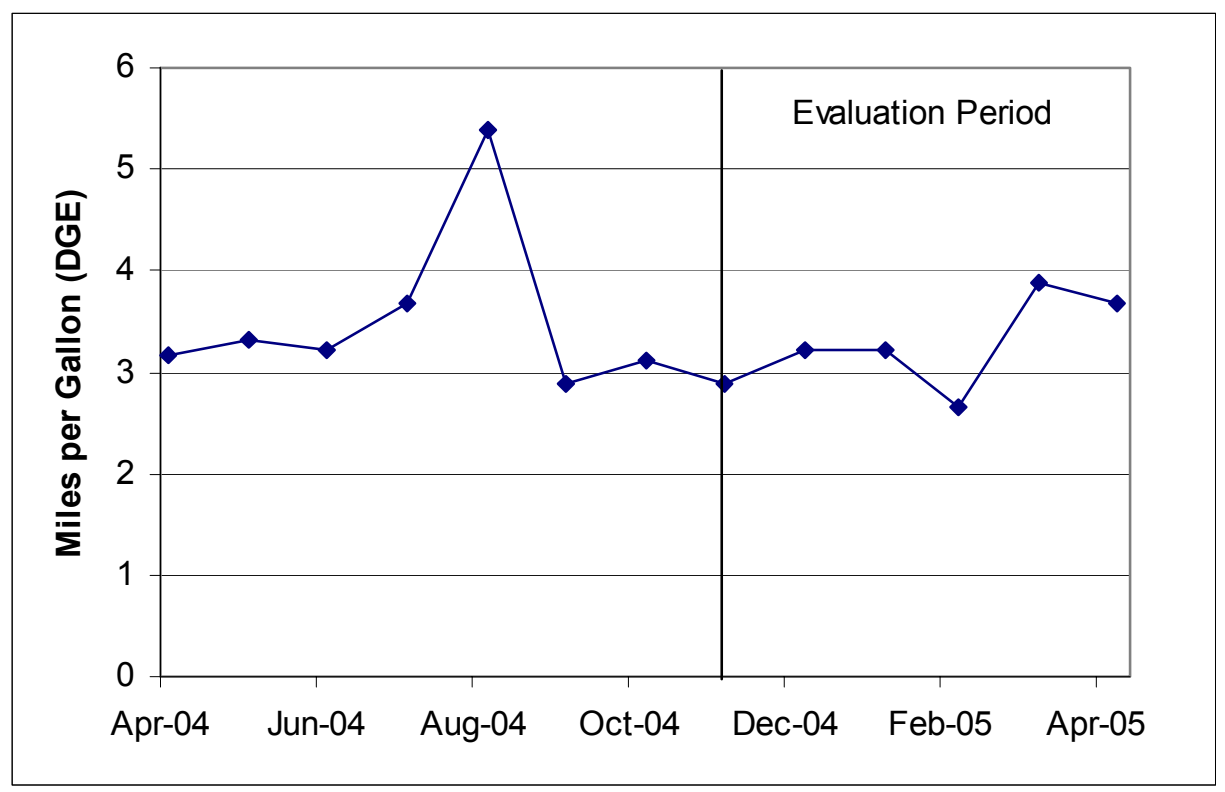

Figure 26. KAT Average fuel economy

\section{Fuel Costs}

LPG was supplied to KAT at a fixed rate of $\$ 0.73$ per gallon for the duration of the evaluation. Table 13 shows fuel cost calculations, which were based on total mileage and fuel volumes recorded during the evaluation period.

Table 13. KAT Fuel Cost Calculations

\begin{tabular}{|c|c|c|c|c|}
\hline Trolley & $\begin{array}{c}\text { Volume LPG Used } \\
\text { (gal) }\end{array}$ & Fuel Cost & Miles Driven & $\begin{array}{l}\text { Fuel Cost } / \\
\text { Mile }\end{array}$ \\
\hline 411 & 943 & $\$ 689$ & 1,688 & $\$ 0.41$ \\
\hline 412 & 1,719 & $\$ 1,255$ & 3,460 & $\$ 0.36$ \\
\hline 413 & 1,530 & $\$ 1,117$ & 3,620 & $\$ 0.31$ \\
\hline 414 & 1,055 & $\$ 770$ & 2,149 & $\$ 0.36$ \\
\hline Total & 5,247 & $\$ 3,830$ & 10,917 & $\begin{array}{r}\$ 0.35 \\
\text { (average) }\end{array}$ \\
\hline
\end{tabular}

\section{Maintenance}

Maintenance cost evaluations were based on the internal work orders generated by KAT during the evaluation period. These work orders were segregated according to vehicle subsystem. Labor and parts costs constitute the maintenance costs, and maintenance-cost-per-mile values were calculated using the miles driven by each trolley during the evaluation period. A standard labor rate of $\$ 50 / \mathrm{hr}$ was used. 
Table 14 indicates the labor hours, part costs, and cost-per-mile values for each trolley during the evaluation period. There are no parts costs because none of the nonwarranty labor done during the evaluation period required parts. Labor and parts replacements done under the warranty were not recorded. In addition, Ebus supplied KAT with extra replacement parts for those thought to have a higher probability of failure. The extra parts, whether they were used or not, were not recorded in the maintenance records. The trolleys averaged $\$ 0.62$ per mile in maintenance costs during the evaluation period.

Table 14. KAT Total Maintenance Cost Comparison (December 2004 to May 2005)

\begin{tabular}{|c|c|c|c|c|}
\hline Trolley & Total Mileage & Labor Hours & Parts Cost & Cost/Mile* \\
\hline 411 & 1,688 & 29 & $\$ 0$ & $\$ 0.86$ \\
\hline 412 & 3,460 & 37 & $\$ 0$ & $\$ 0.53$ \\
\hline 413 & 3,620 & 32 & $\$ 0$ & $\$ 0.44$ \\
\hline 414 & 2,149 & 38 & $\$ 0$ & $\$ 0.87$ \\
\hline Total & 10,917 & 136 & $\$ 0$ & $\begin{array}{r}\$ 0.62 \\
\text { (average) }\end{array}$ \\
\hline
\end{tabular}

${ }^{*}$ At an assumed labor cost of $\$ 50 / \mathrm{hr}$

With advanced technologies, it is important to determine the contribution to maintenance costs of vehicle systems that make up the vehicle's advanced component. Three vehicle subsystems of note- the fuel system, the APU (MicroTurbine), and the electric propulsion system (EPS, including a digital power controller and traction batteries) —were included in the overall evaluation of maintenance costs but also separated for independent assessment and discussion.

Table 15 indicates the labor hours, part costs, and cost-per-mile values for the three hybridrelated subsystems in each trolley. The 12 labor hours attributed to Trolley 414 are the result of three road call events, all of which involved troubleshooting a faulty APU wire harness that was eventually replaced under warranty. During the evaluation period, the trolleys averaged $\$ 0.12$ per mile in maintenance costs for the hybrid-related subsystems. This is approximately $19 \%$ of the overall maintenance cost per mile, as shown in Table 14.

Table 15. KAT Fuel System, APU, and EPS Maintenance Cost Comparison (December 2004 to May 2005)

\begin{tabular}{|r|r|l|r|r|}
\hline Trolley & \multicolumn{1}{|l|}{ Mileage Total } & Labor Hours & Parts Cost & \multicolumn{1}{|l|}{ Cost/Mile* $^{*}$} \\
\hline 411 & 1,688 & 5 & $\$ 0$ & $\$ 0.15$ \\
\hline 412 & 3,460 & 2 & $\$ 0$ & $\$ 0.03$ \\
\hline 413 & 3,620 & 7 & $\$ 0$ & $\$ 0.10$ \\
\hline 414 & 2,149 & 12 & $\$ 0$ & $\$ 0.28$ \\
\hline Total & $\mathbf{1 0 , 9 1 7}$ & $\mathbf{2 6}$ & $\mathbf{\$ 0 . 1 2}$ \\
\hline
\end{tabular}

${ }^{*}$ At an assumed labor cost of $\$ 50 / \mathrm{hr}$

Figure 27 illustrates the cumulative maintenance costs per mile for the trolleys. This approach, summarizing cumulative costs, illustrates how a transit agency may become familiar with a new technology over time. In the early months of implementation, maintenance costs per mile were relatively high. Then, following some variability, these costs decreased and became fairly 
constant during the evaluation period of December 2004 through May 2005. The upward trend for September 2004 to December 2004 is due in part to the troubleshooting and replacement of the APU wire harness, as mentioned earlier, but also to brake repairs, battery cooling system faults, climate control issues, and reports of low SOC.

Figure 27 also illustrates the cumulative hybrid-related systems maintenance cost per mile for the trolleys. In the early months of implementation, maintenance costs per mile were relatively low. After increasing steadily for a while, these maintenance costs decreased and became fairly constant during the evaluation period. This is consistent with KAT's observations of zero to few maintenance issues after receiving the trolleys, followed by a period in which the APU, fuel system, and controls exhibited some unreliability, and, finally, a decline and leveling of monthly maintenance costs related to these systems as problems were resolved.
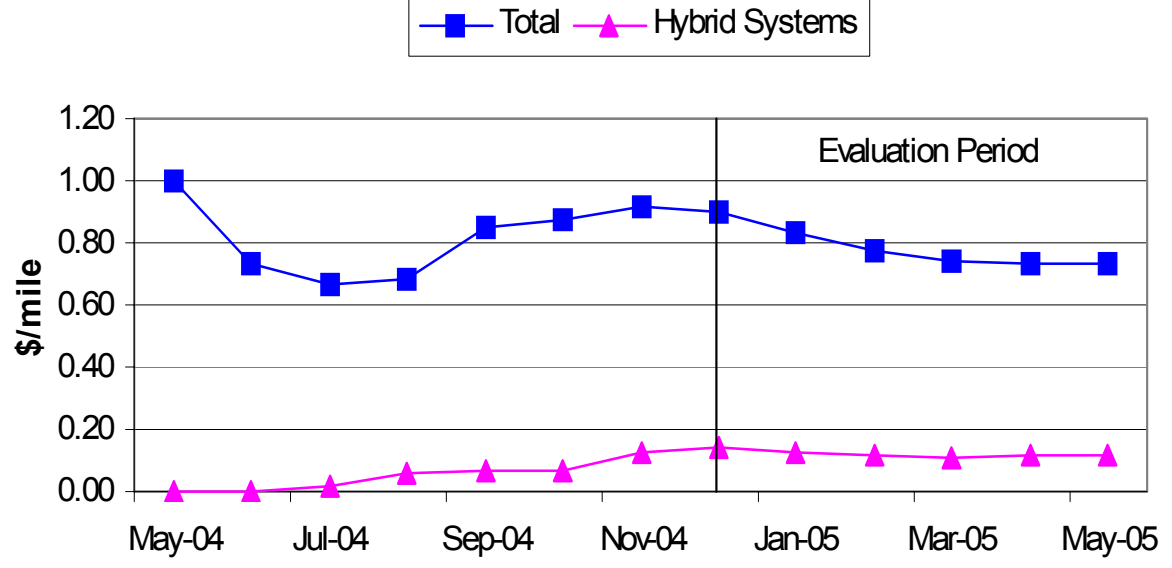

Figure 27. KAT Cumulative maintenance costs per mile

Figure 28 illustrates how maintenance costs were allocated among all vehicle subsystems during the evaluation period. It is important to note that 3.5 hours per month per bus (64\% of the total) can be attributed to KAT's individualized battery pack preventive maintenance procedure. The fuel system, APU, and EPS accounted for 3\%,3\%, and 12\%, respectively, of the total maintenance costs. Propulsion-system-related maintenance costs are broken down further in Figure 29 . The majority $(87 \%)$ of propulsion-system-related maintenance costs were associated with reports of low SOC and turbine fault codes. As described earlier in the IndyGo section, drivers accidentally shutting down the APU might have contributed to low SOC events. The failure of the APU to activate on-route to elevate the battery SOC may have contributed as well. 


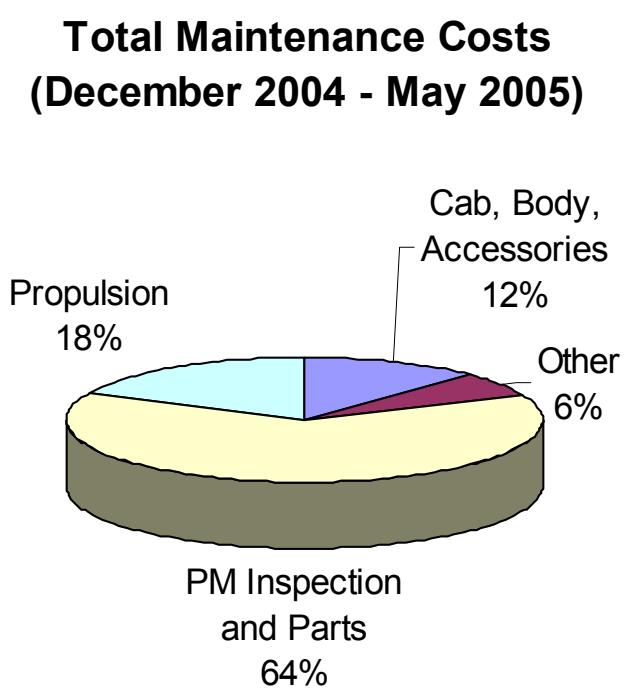

Figure 28. KAT Maintenance costs by vehicle system (Labor + Parts)

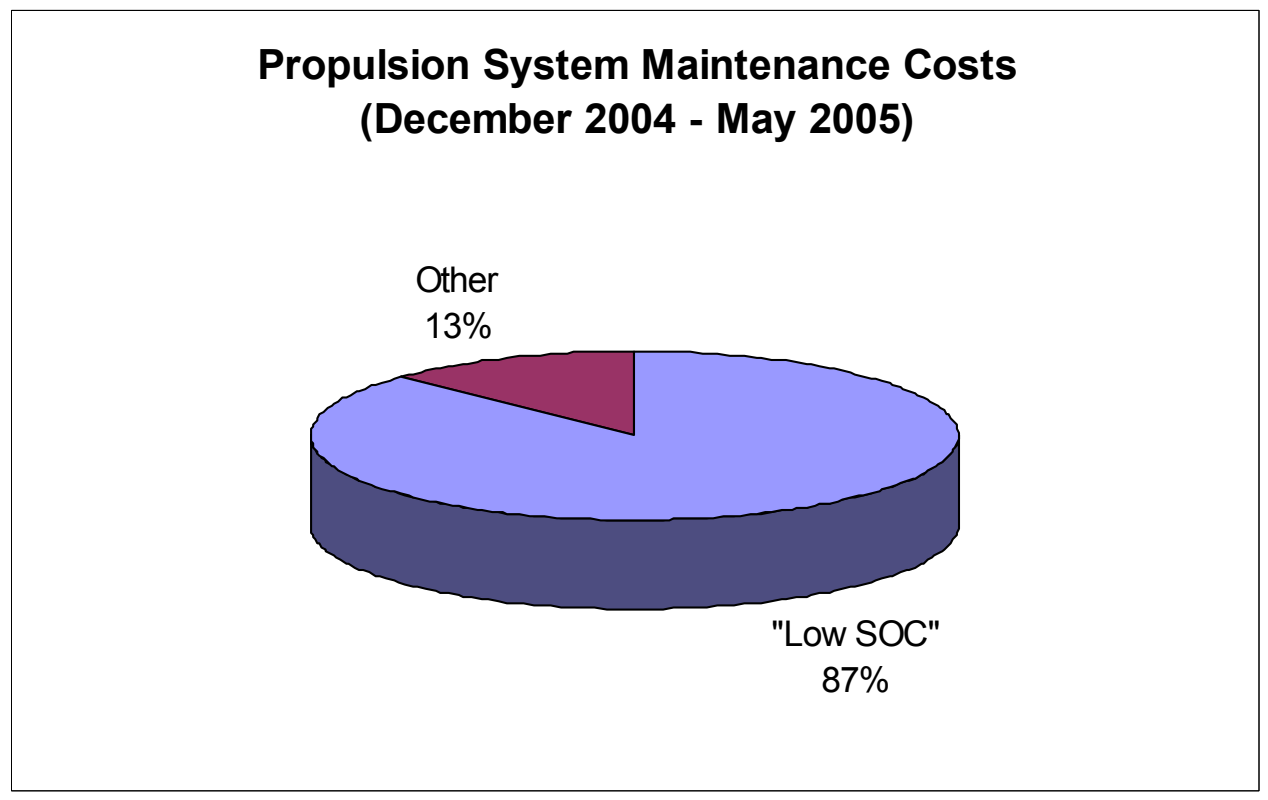

Figure 29. KAT Propulsion system maintenance costs (Labor + Parts)

\section{Specific Component Issues and Resolutions}

Before and during the specific evaluation period, KAT experienced maintenance issues with specific components or vehicle subsystems and performed repairs on them. Many of these components are unique to the Ebus hybrid system, such as the MicroTurbine, the climate control system, and the traction batteries.

\section{Capstone MicroTurbine}

There were several problems with the Capstone MicroTurbine and associated hardware. According to KAT maintenance personnel, fuel injectors failed about three times and were 
replaced under warranty. The DC/DC converters were problematic for all four buses, for a total of about eight independent failures, which were also covered by the warranty. The Capstone wiring harness was also replaced under warranty.

KAT noted a turbine fault code (2011) intermittently at startup, which prevented the turbine from firing. The solution was to cut $12 \mathrm{~V}$ of power to the computer, thus overriding the fault and allowing the turbine to start. The cause of the fault code was unknown, and so a direct fix proved to be elusive.

\section{Climate Control}

The climate control system encompasses the heating and cooling systems. Knoxville's relatively wide range of temperatures and the Red Line's large customer base together placed considerable demands on the climate control system.

The trolley's low floor, small internal volume, and large door--which opened frequently to admit and release customers - made it a challenge to maintain a comfortable inside temperature yearround. One complaint voiced by KAT mechanics and drivers was that the climate control system was too small to keep up with the fan.

The heating unit is fueled with kerosene. One heating unit failed and was replaced under warranty by Ebus.

\section{Traction Batteries}

In general, the traction batteries performed well. However, low charge was cited as the reason for several road calls throughout the evaluation period. The response and actions taken by KAT maintenance personnel included cleaning and charging the batteries.

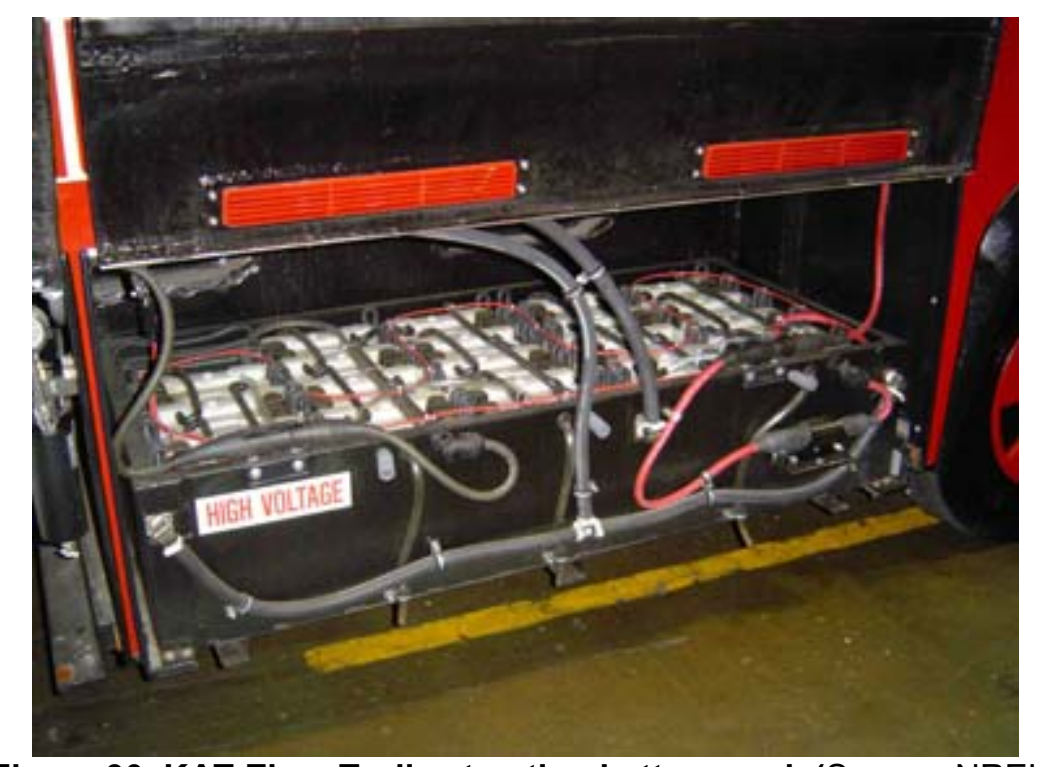

Figure 30. KAT Ebus Trolley traction battery pack (Source: NREL)

To reduce battery-related road calls, KAT personnel enacted an individualized preventive maintenance routine created specifically for the traction battery pack. This routine, which was 
carried out in 2-week intervals, consisted of cleaning the batteries with a vinegar spray and then rinsing them with water.

\section{Campaigns}

Several campaigns to replace or upgrade components were conducted during the evaluation. Table 16 lists the campaigns that occurred during 12 months of data collection at KAT.

Table 15. Campaigns

\begin{tabular}{|l|l|l|}
\hline Campaign Item & Date & Reason/Description \\
\hline AC/Heater Replacement & June 2004 & $\begin{array}{l}\text { TransAir system prone to failure, so } \\
\text { campaign carried out at several transit } \\
\text { properties }\end{array}$ \\
\hline $\begin{array}{l}\text { Insulate High-Voltage Wire } \\
\text { and Fuse Adjacent to Battery } \\
\text { Pack }\end{array}$ & September 2004 & $\begin{array}{l}\text { Fire-prevention effort following incident } \\
\text { at IndyGo }\end{array}$ \\
\hline Chargers and Computers & $\begin{array}{l}\text { April 2005, May } \\
2005\end{array}$ & $\begin{array}{l}\text { Requested larger capacity charger; } \\
\text { computer replacement necessary to } \\
\text { interface with new charger }\end{array}$ \\
\hline
\end{tabular}

\section{Road Calls}

KAT uses a broad definition of a road call that depends primarily on the driver's perceptions. When a driver makes a road call, a mechanic is dispatched to make an evaluate and repairs, if necessary. Some repairs can be made roadside during the time a trolley dwells at a turnaround; others might require towing the trolley back to the garage.

According to KAT, the trolleys were generally reliable on the route, provided that they were warmed up before use. Because KAT used such a comprehensive definition for a road call, it is not clear how many road calls defined as such necessitated a tow back to the KAT garage. According to KAT maintenance personnel, only three tow-in events occurred and one of them was driver-related (caused by insufficient driver training rather than a legitimate problem with the trolley).

The bulk of the road calls relating specifically to the EPS were triggered by a driver's complaints of "low power" or "low charge." Except for one incident in which no problem was detected, the action taken at all road calls was to clean and charge the batteries or check and clear codes. A December 2004 road call described by a driver as "low LPG" was caused by low fuel on the route. This event corresponded to the period when KAT had only one charger for overnight opportunity charging. This event prompted the implementation of self-charging, as described earlier. Table 17 is a summary of road calls during the evaluation period. 
Table 16. KAT Road Call Comparison

(December 2004 to May 2005)

\begin{tabular}{|c|r|r|}
\hline Trolley & $\begin{array}{c}\text { Total Road } \\
\text { Calls }\end{array}$ & $\begin{array}{c}\text { Fuel, APU, EPS } \\
\text { Road Calls }\end{array}$ \\
\hline 411 & 1 & 1 \\
\hline 412 & 5 & 1 \\
\hline 413 & 5 & 3 \\
\hline 414 & 6 & 6 \\
\hline Total & $\mathbf{1 7}$ & $\mathbf{1 1}$ \\
\hline
\end{tabular}

Figure 31 shows the trend for the cumulative MBRC. This depiction of the frequency of road calls illustrates the variability of this metric in the early stages of implementing the Ebus trolleys; this was followed by a drop in MBRC and more stability during the evaluation period. The average MBRC during the evaluation period was approximately 1,000 MBRC, which, given the road call definition above, includes events that did not require a tow to the garage. The trend line begins with July 2004, because there were no road calls in May or June 2004.

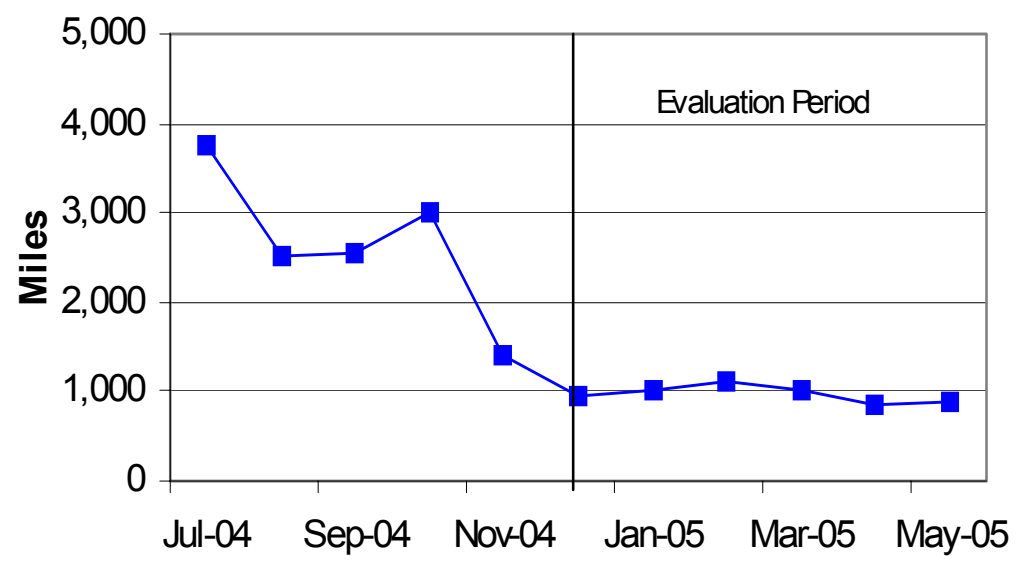

Figure 31. KAT Cumulative miles between road calls (MBRC)

The high MBRC values are primarily the result of low-charge issues. Once KAT applied its personalized battery preventive maintenance practices, the number of these road calls decreased for all trolleys except trolley 414.

\section{Total Operating Costs}

The total operating cost per mile driven is an important metric to fleets, especially when they are evaluating a new technology. Here, total operating costs are based on the maintenance and fuel costs accrued during the evaluation period and are presented in Table 18. A comparison of fuel and maintenance costs to the overall cost per mile is shown in Figure 32. On average, the trolleys cost $\$ 0.97$ per mile to operate during the evaluation period. The high total cost per mile values for trolleys 411 and 414 were driven by high maintenance cost per mile values. 
Table 17. KAT Total Operating Cost Comparison

\begin{tabular}{|r|r|r|r|r|r|}
\hline Trolley & Miles Driven & Labor Hours & Parts Cost & Fuel Cost & Cost/Mile \\
\hline 411 & 1,688 & 29 & $\$ 0$ & $\$ 689$ & $\$ 1.27$ \\
\hline 412 & 3,460 & 37 & $\$ 0$ & $\$ 1,255$ & $\$ 0.90$ \\
\hline 413 & 3,620 & 32 & $\$ 0$ & $\$ 1,117$ & $\$ 0.75$ \\
\hline 414 & 2,149 & 38 & $\$ 0$ & $\$ 770$ & $\$ 1.23$ \\
\hline Total & $\mathbf{1 0 , 9 1 7}$ & $\mathbf{1 3 6}$ & $\mathbf{\$ 0}$ & $\mathbf{\$ 3 , 8 3 0}$ & $\begin{array}{r}\mathbf{\$ 0 . 9 7} \\
\text { (average) }\end{array}$ \\
\hline
\end{tabular}

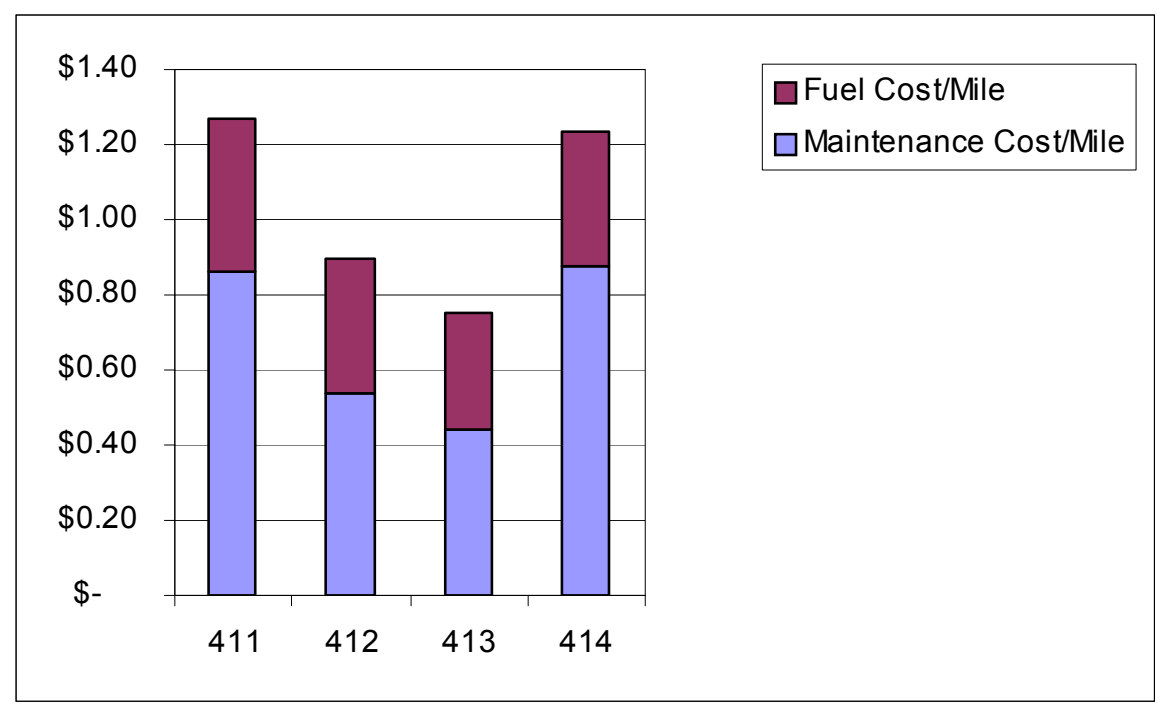

Figure 32. KAT Cost per mile source breakdown

\section{Summary of Results for KAT}

Overall, the Ebus trolleys met KAT's goals. KAT desired a clean-fuel, low-emissions solution to alleviating downtown congestion during peak commuter hours, and the LPG Ebus hybrid trolley met that goal.

- Applicability: This was satisfactory and primarily the result of KAT identifying the application and vehicle requirements and allowing Ebus to tailor the vehicle to fit those requirements.

- Availability: The Ebus trolleys met KAT's requirements for availability, with a few caveats. Of KAT's four trolleys, two could be on the route at any time and two were spares. This spare ratio exceeds the industry norm and far exceeds KAT's typical ratio.

- Reliability: With appropriate warm-ups and a short duty cycle, the vehicles were reliable and met KAT's requirements.

$\bullet$

KAT learned two important lessons during the evaluation:

- It is important to match a vehicle to an appropriate duty cycle. KAT's thorough research before ordering and implementing the Ebus trolleys was validated by a relatively smooth experience with them. 
- Frequent training of drivers and mechanics is necessary when implementing a new technology. Time and effort invested in training programs offset the initial increase that is likely in road calls and maintenance costs.

In the future, KAT plans to expand its fleet with 30-foot LPG-fueled trolleys. There are no plans to purchase additional Ebus trolleys, as there are no plans to expand service for the Red Line or another similar route.

\section{Overall Summary and Comments}

To move forward with a technical development effort that would help reduce air and noise pollution, IndyGo and KAT independently decided to purchase several Ebus hybrid electric vehicles. Both agencies are relatively small in both size and resources, but they were able to secure partial funding for their development through CMAQ grants. Since the Ebus hybrid electric buses and trolleys are specialty items, downtown circulator routes were created for their application.

Three overarching lessons were learned in this process. They involve matching the vehicle to an appropriate duty cycle, training drivers and maintenance personnel thoroughly, and understanding that new technologies are often still in the development stage.

\section{Match the Vehicle to the Duty Cycle}

When the buses and trolleys were operated for shorter blocks of time, they were more successful in several indicators: miles between road calls, trends in fuel economy, and repair costs incurred. KAT started and maintained a small-scale duty cycle for the trolleys that proved to be reasonably successful. KAT's Red Line utilized two trolleys during two blocks of time for a total of 5.5 hours per day per trolley. IndyGo chose a longer duty cycle than KAT, with 12 hours of operation per day per bus. It became a daily challenge for IndyGo to keep three of the five buses in service at one time. This limited availability caused IndyGo to reduce usage to less than onethird of the planned schedule. With reduced usage, the indicators for the IndyGo buses showed a reasonable amount of success.

In general, KAT had fewer maintenance complications than IndyGo did. This can be attributed to both the shorter duty cycle and the different fuels used. LPG may have been a more appropriate fuel for the turbine technology. The diesel-turbine combination that IndyGo used had not been tried before. Ebus reports that diesel fuel is more difficult to ignite in the MicroTurbine. Capstone is therefore developing improved igniters. Also, the diesel-fueled MicroTurbine requires a diesel fuel pump, an additional part that is not necessary with an LPG-fueled MicroTurbine.

\section{Train Drivers and Maintenance Personnel}

Another fundamental lesson that each fleet learned was the need to expand the depth and breadth of training for both drivers and maintenance personnel. Both transit properties stressed that education was important for all employees exposed to a new technology, as the many subtle differences can be a cause of increases in road calls and maintenance costs. 
Successful experiences at KAT and IndyGo were driven by employees' dedication to making a new technology work. For instance, both transit properties had one lead mechanic who invested in learning new maintenance techniques for these trolleys and buses. During the early stages of implementation, a maintenance technician at IndyGo changed out a turbine with only phone assistance from Ebus. This shows a willingness to learn new things to make a technology work. Both transit properties were satisfied with the assistance that Ebus provided.

The successful use of these buses at a small transit property was also largely the result of the adaptability of key employees who interface with advanced technology on a day-to-day basis. This level of dedication also extends to driver training. Not assigning drivers consistently to the circulator route with the Ebus buses caused some "hiccups" in the number of road calls for IndyGo. More consistency in driver assignments, training, and experience would have reduced the number of these road calls.

\section{New Technology Is Still in Development}

The hybrid-electric propulsion system that incorporates a MicroTurbine is a relatively young vehicle technology. In fact, the first application of diesel fuel in a MicroTurbine for a vehicle was at IndyGo. IndyGo struggled more than KAT with low-SOC road calls, which accounted for $32 \%$ of IndyGo's propulsion-related maintenance costs. Many of these costs were the result of a driver's error, however, and some were caused by the failure of the Capstone igniter to activate the MicroTurbine.

Capstone is therefore developing improved igniters, and Ebus conducted a software campaign at IndyGo in spring 2005 to address this issue. As noted earlier, this made the MicroTurbine run all the time at a reduced level rather than cycle on and off to maintain a prescribed battery SOC. This was a relatively significant change to the propulsion system design and was made only at IndyGo.

Despite low-SOC road calls and reduced availability, the Ebus hybrid electric vehicles were somewhat successful. Specifically, KAT experienced a relatively successful application of the trolleys by using them on a short, light, duty cycle. At this stage, both agencies are using the vehicles in specialty applications. Both transit experiences showed the need to carefully train employees who interact with the technology on a day-to-day basis, as well as to monitor and not exceed the application of these vehicles. 


\title{
Contacts
}

\author{
U.S. Department of Energy \\ Lee Slezak \\ Manager, Advanced Vehicle Testing Activity \\ 202-586-2335 \\ lee.slezak@ee.doe.gov \\ IndyGo \\ Morris Frye \\ Director, Vehicle Maintenance \\ 317-614-9309 \\ morris@indygo.net \\ KAT \\ Robert Schneider \\ Chief Operating Officer \\ 865-215-7803 \\ rschneider@cityofknoxville.org \\ Ebus \\ Andy Eklov \\ 562-904-3474 \\ eklov@ebus.com \\ NREL \\ Robb Barnitt \\ Project Engineer \\ 303-275-4489 \\ robb_barnitt@nrel.gov
}




\section{Acronyms and Abbreviations}

\begin{tabular}{|c|c|}
\hline APU & advanced power unit \\
\hline AVTA & Advanced Vehicle Testing Activity \\
\hline bhp & brake horsepower \\
\hline CARB & California Air Resources Board \\
\hline CMAQ & Congestion Mitigation Air Quality \\
\hline $\mathrm{CNG}$ & compressed natural gas \\
\hline $\mathrm{CO}$ & carbon monoxide \\
\hline DGE & diesel gallon equivalent \\
\hline DOE & U.S. Department of Energy \\
\hline DPF & diesel particulate filter \\
\hline EPA & U.S. Environmental Protection Agency \\
\hline EGR & exhaust gas recirculation \\
\hline $\mathrm{g} / \mathrm{bhp}-\mathrm{hr}$ & grams per brake horsepower-hour \\
\hline GVWR & gross vehicle weight rating \\
\hline $\mathrm{HC}$ & hydrocarbons \\
\hline $\mathrm{HEV}$ & hybrid electric vehicle \\
\hline HVAC & heating, ventilation, and air-conditioning \\
\hline IndyGo & Indianapolis Transportation Corporation \\
\hline KAT & Knoxville Area Transit \\
\hline $\mathrm{kW}$ & kilowatt \\
\hline LPG & liquefied petroleum gas \\
\hline MBRC & miles between road calls \\
\hline $\mathrm{NiCd}$ & nickel cadmium \\
\hline NREL & National Renewable Energy Laboratory \\
\hline NMHC & nonmethane hydrocarbons \\
\hline $\mathrm{NOx}$ & oxides of nitrogen \\
\hline PM & particulate matter \\
\hline ppm & parts per million \\
\hline $\mathrm{RC}$ & road call \\
\hline $\mathrm{rpm}$ & revolutions per minute \\
\hline SOC & state of charge \\
\hline $\mathrm{V}$ & volt \\
\hline
\end{tabular}




\section{References}

Ebus Web site, www.ebus.com.

Eudy, L., Gifford, M., Challenges and Experiences with Electric Propulsion Transit Buses in the United States, DOE/GO-102003-1791, Golden, CO: National Renewable Energy Laboratory, 2003.

NREL, Advanced Technology Vehicles in Service, Knoxville Area Transit, DOE/GO-1020052085, Golden, CO: National Renewable Energy Laboratory, 2005.

NREL, Advanced Technology Vehicles in Service, Indianapolis Public Transportation, DOE/GO-102004-1986, Golden, CO: National Renewable Energy Laboratory, 2004.

NREL, General Evaluation Plan, Fleet Test \& Evaluation Projects, NREL/BR-540-32392, Golden, CO: National Renewable Energy Laboratory, 2002.

The Pennsylvania Transportation Institute, STURAA Test, 7 Year 200,000 Mile Bus from Ebus, Inc. Model Vintage Trolley, PTI-BT-R0121, Altoona, PA: PTI, 2002. 


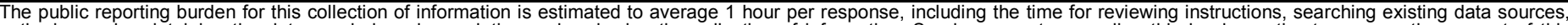

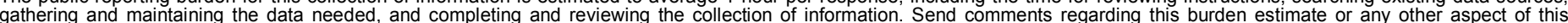

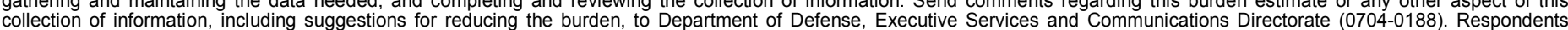

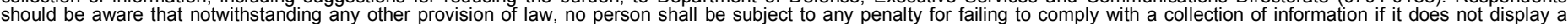

should be aware that notwithstanding

PLEASE DO NOT RETURN YOUR FORM TO THE ABOVE ORGANIZATION.

\begin{tabular}{l|l|l|l} 
1. REPORT DATE $(D D-M M-Y Y Y Y)$ & 2. REPORT TYPE & 3. DATES COVERED (FrOm - TO)
\end{tabular}

July 2006

Technical Paper

4. TITLE AND SUBTITLE
Case Study: Ebus Hybrid Electric Buses and Trolleys

5a. CONTRACT NUMBER

DE-AC36-99-G010337

5b. GRANT NUMBER

5c. PROGRAM ELEMENT NUMBER

6. AUTHOR(S)

R. Barnitt

5d. PROJECT NUMBER

NREL/TP-540-38749

5e. TASK NUMBER

FC06.3000

5f. WORK UNIT NUMBER
7. PERFORMING ORGANIZATION NAME(S) AND ADDRESS(ES)

National Renewable Energy Laboratory

1617 Cole Blvd.

Golden, CO 80401-3393
8. PERFORMING ORGANIZATION REPORT NUMBER

NREL/TP-540-38749

9. SPONSORING/MONITORING AGENCY NAME(S) AND ADDRESS(ES)

10. SPONSOR/MONITOR'S ACRONYM(S) NREL

11. SPONSORING/MONITORING AGENCY REPORT NUMBER

12. DISTRIBUTION AVAILABILITY STATEMENT

National Technical Information Service

U.S. Department of Commerce

5285 Port Royal Road

Springfield, VA 22161

13. SUPPLEMENTARY NOTES

14. ABSTRACT (Maximum 200 Words)

This evaluation focuses on the demonstration of hybrid electric buses and trolleys produced by Ebus, Inc.

(www.ebus.com), of Downey, California. Ebus manufactures 22-foot buses with a variety of optional powertrains and exterior designs. The vehicles come with battery electric and hybrid electric powertrain options, and purchasers can choose either conventional bus or antique-trolley-style exteriors. The Indianapolis Transportation Corporation (IndyGo) and Knoxville Area Transit (KAT) participated in a demonstration of the Ebus vehicles. Each fleet chose hybrid electric powertrains but selected different exterior designs and fuels.

15. SUBJECT TERMS

Hybrid electric; buses; trolleys; Ebus Inc.; Indianapolis Transportation Corporation; IndyGo; Knoxville Area Transit; KAT; evaluation; U.S. Department of Energy; DOE; Advanced Vehicle Testing Activity; AVTA; National Renewable Energy Laboratory; NREL

\begin{tabular}{|l|l|l|l|l|}
\hline \multicolumn{3}{|l|}{ 16. SECURITY CLASSIFICATION OF: } & $\begin{array}{c}\text { 17. LIMITATION } \\
\text { OF ABSTRACT }\end{array}$ & $\begin{array}{c}\text { 18. NUMBER } \\
\text { OF PAGES }\end{array}$ \\
\hline $\begin{array}{l}\text { a. REPORT } \\
\text { Unclassified }\end{array}$ & $\begin{array}{c}\text { b. ABSTRACT } \\
\text { Unclassified }\end{array}$ & $\begin{array}{c}\text { c. THIS PAGE } \\
\text { Unclassified }\end{array}$ & $\begin{array}{c}\text { UL } \\
\end{array}$ &
\end{tabular}

19a. NAME OF RESPONSIBLE PERSON

19b. TELEPHONE NUMBER (Include area code) 